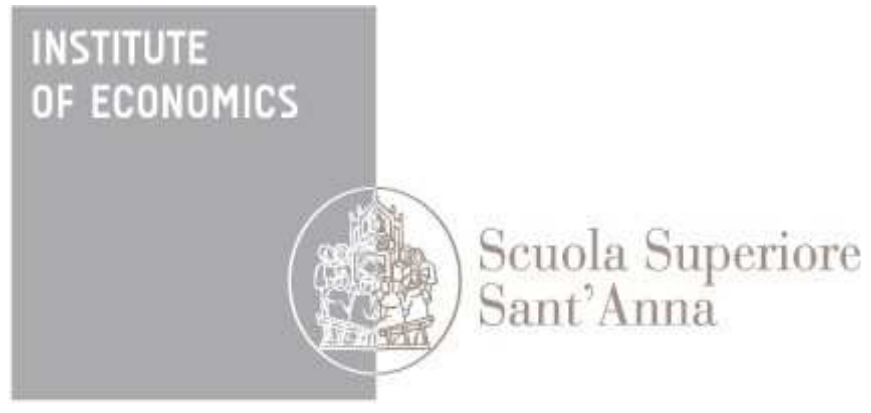

LEM | Laboratory of Economics and Management

Institute of Economics

Scuola Superiore Sant'Anna

Piazza Martiri della Libertà, 33 - 56127 Pisa, Italy ph. +3905088.33 .43$

institute.economics@sssup.it

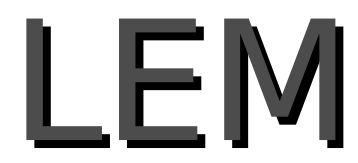

Working Paper Series

\title{
Where does the surplus go? Disentangling the capital-labor distributive conflict
}

Francesco Bogliacino ${ }^{\circ}$

Dario Guarascio *

Valeria Cirillo $\S$

-Universidad Nacional de Colombia

* University of Rome "La Sapienza", Italy

${ }^{\S}$ Institute of Economics, Scuola Superiore Sant'Anna, Pisa, Italy 


\title{
Where does the surplus go? \\ Disentangling the capital-labor distributive conflict
}

\author{
Francesco Bogliacino \\ Universidad Nacional de Colombia \\ fbogliacino@unal.edu.co
}

Dario Guarascio

Sapienza University of Rome

Corresponding Author: dario.guarascio@uniroma1.it

Dept. of Economics and Law, Faculty of Economics - Sapienza University of Rome

Via del Castro Laurenziano 9, 00185 Rome

\author{
Valeria Cirillo \\ Scuola Superiore Sant'Anna, Istituto di Economia, Pisa \\ v.cirillo@sssup.it
}

\begin{abstract}
The evidence on growing inequality in OECD countries has raised an important debate over its main drivers, pointing out an increasing importance of the capital-labour conflict. In this contribution, we aim at disentangling the role of some of the forces shaping this process. Our identification strategy relies on the sequential nature of wage setting and profits realization, in line with theoretical insights from the range theory of wages (postulating rents sharing at the shop floor level) and the principle of effective demand. In particular we focus on the role of technology and offshoring as instruments to create surplus and to shape the bargaining power of the parties involved in wage setting, and on different sources of demand as heterogeneous determinants of profits realization. The empirical analysis is performed on a panel of 38 manufacturing and service sectors over four time periods from 1995 to 2010, covering Germany, France, Italy, Spain, and United Kingdom. The contrasting effects of R\&D and offshoring emerge as determinants of wages. Investment and internal demands are key variables in the realization of profits. When we look at the heterogeneity of the effects we see three main stylized facts. First of all, distinguishing for technological domain using Pavitt classes we can see that rents are effectively related with upgraded industries. Secondly, when we distinguish for the degree of openness we can see that, again, rents are mainly shared in open industries. Finally, when we disentangle the effect on wages per skill level, it is possible to confirm the intuition that offshoring hits the medium-low skill categories.
\end{abstract}

Keywords: rent; surplus; distribution; inequality; offshoring; R\&D

JEL Classification: O33, F15, J31 


\section{Introduction}

Income inequality has been increasing in the post 1980s decades in most OECD countries, although with some degree of heterogeneity both in terms of magnitude and timing. This has been certified by two comparative studies of the $\operatorname{OECD}(2008 ; 2011)$ and by a recent work by Bogliacino and Maestri (2014). In these studies, inequality is measured as the Gini of net equivalized disposable income, calculated as the sum of market income flows, adjusted for the state intervention through taxes and subsidies and taking into account the economies of scale inside the household. It is possible to identify the proximate causes of the variations of this aggregate indicator. By proximate causes, it is meant those factors that explain statistically the change, but cannot be considered final causes because they are codetermined by inequality in the overall distribution. As discussed by Bogliacino and Maestri (2014) this distinction between proximate drivers and causes should be taken into account when analyzing inequality: e.g. without a clear theoretical distinction between exogenous sources and endogenous changes, the inference (e.g. regarding policies) will never be correctly specified.

The evidence suggests that most of the variation of inequality should be imputed to the earnings distribution. This is not surprising since earnings represent the most common source of disposable income across households and, thus, a change in its own distribution has a first order effect over the total income inequality. However, the capital-labor conflict has an increasing role in explaining the change in the Gini: since capital income is more unequally distributed than labor, a reduction of the labor share increases total inequality. The increase in the capital share has been remarkable in most OECD countries (Arpaia et al., 2009; Checchi and GarciaPenalosa, 2010; Stockhammer; 2013; Schlenker and Schmid, 2013; Van der Hoeven, 2014; ILO, 2015).

However, there are further reasons to deepen our understanding of the capital-labour distribution. On the empirical side, most of the profits go into the top one percent and it is already known that the Gini is mainly sensible to changes around the "middle class" (Atkinson et al. 2011; Bogliacino and Maestri, 2014). This would even be clearer if performance related payments of managers were computed inside the profit share instead of misleadingly being included in the labour one (Stiglitz, 2012).

On the theoretical side, profits are the main driver of accumulation in capitalist economy and the importance of the capital in understanding modern economy has been recently relaunched by Piketty's work (Piketty, 2014). If profits are the drivers, it is obvious that in reality we cannot treat labour market, technical change or globalized institutional settings in isolation with respect to the capital-labour relationship.

Nevertheless, this is precisely the kind of partial focus that has been adopted by scholars studying inequality. The most popular explanations of the post 1980s increase in inequality have 
been concerned only with labour market, suggesting that either trade or technical change have been driving the increasing dispersion of earnings.

In fact - mainstream approach suggests - since OECD economies are relatively abundant in skilled labour, compared with emerging economies, one should expect the skill premium to increase in the former and decrease in the latter, by a simple Hecksher-Ohlin logic. Nevertheless, the evidence suggests that skill premium increased in both developed and developing countries (Acemoglu, 2002; Acemoglu and Autor, 2011). Moreover, most of the increase in inequality is within sector, contradicting the hypothesis that comparative advantages (which are reflected in changes between sectors) are the main driver (Bogliacino and Maestri, 2014). This somehow benefitted the view that technical change should be considered the main responsible for the increase in inequality, a view popularized as Skill Biased Technical Change. In this article we propose a more "classical approach" (Ricardo, 1815; Marx 1867) were functional distribution is put at the centre of the stage and forces that affect the labour market are discussed inside a common framework where distributive conflict is related with both the realization of profits inside the market and the generations of rents related with technological change and the organization of production.

In other words, we agree with Howell (1999) that one of the main problems in existing explanations is precisely the dominance of a very simple demand-supply model of the labour market, which somehow frame the discussion and support a theory-driven interpretation. At the opposite, within a range of possible wage profiles that are determined not only by demand and supply, but also by social norms and by policy constrains, there is a genuine bargaining by firms and employees (Howell, 1999; Atkinson, 1999). This institutions embedded labour market should be also conceptualized as part of an economy where rents are continuously created, and relatively slowly shared, as in the standard Schumpeterian framework.

In our theoretical framework, wage setting is determined by total employment, capital installed and total production as in standard demand and supply framework, together with international organization of production and technical change that determine the surplus to be shared. Once bargained, the wage represent a constraint by the capital to realize profits, and the market realization depends upon various source of demand as in standard Kaleckian and postKeynesian framework (Kalecki, 1939; Arestis, 1996).

We apply our framework to industry level data for five European countries (Germany, France, Italy, Spain, and United Kingdom) over the period 1995-2010. Our database is the result of the merge of Community Innovation Survey, OECD STAN and WIOD data, allowing measurement of different sources of demand, technology and offshoring.

Our work is related with a number of different literatures. First of all, we share with an increasing stream of contributions the methodological choice of using industry level data. As explained in a series of recent papers (Lucchese and Pianta, 2012; Bogliacino and Pianta, 2013a; 
2013b; Guarascio et al., 2014 and 2015) this type of analysis is aimed at capturing the structural heterogeneity in the economy, related with demand and technology, while maintaining overall account of the macro balance: the sum of the industries is by construction the total economy, while this does not apply to firm level data where representativeness is usually failing because of sample selection. Regarding the role of structural differences, on the one hand, demand by definition is not a constraint at firm level, where business stealing allows firms to grow at the expenses of the competitors, but it is downward sloping at industry level. Secondly, technological trajectories are only partly captured at micro level through proxies of technical change, while industry level variable internalize at least partially the knowledge base and the spillovers, which are related with a certain sectoral system of innovation (Dosi, 1988; Malerba, 2004).

Secondly, our article is close in spirit to those contributions that try to unravel the distributive conflict in capitalist economies (Pianta and Tancioni, 2008; Basu and Vasudevan, 2013). Pianta and Tancioni (2008) carried out a previous attempt to analyze - empirically and at the industry level - the effect of technical change distinguishing product and process innovation on the functional distribution of income. The authors have found that profits are driven by the 'Schumpeterian' effects of new products. Wages, on the contrary tend to be pushed upwards by new products, in highly innovative sectors, whereas process innovation drive them downwards in low-tech industries. Similar analysis have been carried out in post Keynesian literature, with which our work share the emphasis on demand as a fundamental source of profits realization. For example, Stockhammer (2013) analyzes the declining wage share in OECD countries, claiming that the larger determinants are technological change, offshoring, financialisation, globalisation and retrenchment of welfare state. ${ }^{1}$

Thirdly, our article critically discusses the mainstream claim that Skill Biased Technical Change is to be considered as the main responsible of increasing income inequality. In modern economic theory, the idea that technical change is not neutral is probably due to Hicks (1932) although labor saving bias of machines was clearly present in Marx and Ricardo -, which suggests that labor saving innovation is driven by falling prices of capital. Hicks' statement generated a large discussion over whether it is possible or not to discriminate a priori a bias of technology (Salter, 1960), or over the technical conditions - e.g. in terms of elasticity of substitution among factors - necessary to determine an induced bias (Fellner, 1961; Kennedy, 1964; Samuelson, 1965; Von Weiszacker, 1966; Drandrakis and Phelps, 1966 and, more recently, Zamparelli, 2011).

\footnotetext{
${ }^{1}$ See also Tridico (2012) for the relationship between the labour share, its drivers and the financial crisis, and Jayadev (2007) for the importance of capital liberalization.

${ }^{2}$ The causal relationships among offshoring, profits and innovation have been recently investigated both
} 
This theoretical discussion of the 1960s have been revived in the 1990s, to explain the increasing college premium in the US, and following stylized facts by Berman et al. (1994) relating the massive introduction of ICT technologies and the dynamics of wages. A large theoretical literature has been developed afterwards, suggesting that new technologies complement skills (Acemoglu, 2002; Acemoglu and Autor, 2011). The theory of SBTC has two main shortcomings: first of all, it is not clear if the bias is endogenous or exogenous. According to Acemoglu and Autor (2011) the bias should be made endogenous to the variations of the supply of skills, changing the patterns of incentives of those inventing new machines complementing them. Nevertheless, Bogliacino and Lucchese (2015) use the German reunification shock over West Germany as a natural experiment in the variation of the supply of skill, but do not find any evidence of SBTC.

As a second shortcoming, as explained in OECD (2011) and Bogliacino and Maestri (2014), institutional reforms in the labour markets appear to be responsible for most of the change in wage inequality. As we argue, the conceptual problem related with SBTC is that technology per se creates rents. The way in which those rents are shared should be made dependent on a bargaining between labour and capital (and where institutional factors certainly play a role). We build on Van Reenen (1996) and Bogliacino (2014) to put forth a simple model of rent sharing related with innovative effort.

Finally, our work introduces the international fragmentation of production as a key determinant of the rent-sharing model of wages. A growing literature since the late Nineties has introduced the expression of "new wave of globalization", to describe the evolution of world trade in which the international exchange of finished goods is slowly replaced by the increasing exchange in intermediate and semi-finished goods and services (Feenstra and Hanson, 1996; Campa and Goldberg, 1997; Hummels et al., 2001; Milberg and Winkler, 2010 and 2013). In particular the emphasis is on offshoring, which seems to be interplaying with technical change. ${ }^{2}$

The empirical literature provides mixed evidence concerning the impact of offshoring on wages and profits. If, on the one hand, offshoring brings benefit to firms and consumers in terms of lower production costs and lower prices for final goods; on the other hand, it may results in

\footnotetext{
${ }^{2}$ The causal relationships among offshoring, profits and innovation have been recently investigated both empirically and theoretically. Nevertheless, the question if there exists a virtuous cycle in which international outsourcing, able to generate profits that feed increased innovation, still remains unanswered. Glass and Saggi (2001) have proposed a theoretical model in which firms' offshoring - in particular, a cost-motivated one - ensures efficiency gains that feed higher innovation. Higher innovation can then turns back in increased offshoring due to the permanence of a 'technology gap'. They describe an innovation-profit channel alimented through the efficiency gains of offshoring. However, convincing empirical evidence concerning the existence of such channel is still missing.
} 
large employment losses among low skilled workers and increasing wage differential (Feenstra and Gordon, 1997; Feenstra and Hanson, 1996 and 1999; Amiti and Wei, 2004;).

In terms of offshoring and wages, Antràs et al. (2006) argue that the effect of offshoring on wages is negligible and the only impact, despite moderate, is a positive one on high skilled workers located in the offshoring countries. Using a multi-country model of international trade, Burstein and Vogel (2012) detect a positive relationship between offshoring and high skilled wages but without any relation with countries' skill endowments. Costinot et al. (2013) find that the impact of offshoring on wages is strongly heterogeneous due to the different skill composition of industrial sectors. Furthermore, Sheng and Yang (2012) show how offshoring related exports and FDI are at the root of the Chinese college wage premium. Another group of contributions (among the others Slaughter, 2000 and Geishecker and Görg, 2008) support the thesis that offshoring negatively affects the employment level and the wage share of low-skilled workers in developed economies. Foster et al. (2012) analyze the impact of offshoring on labour demand elasticity for a group of 40 countries over the period 1995-2009, detecting a neutral effect of offshoring on aggregate employment, which turns into negative for low and medium educated workers.

Regarding offshoring and profits, Görg and Hanley (2011) estimated the impact of service offshoring on firms' profits and innovative behavior. Using a sample of 1929 Irish plants they found a positive effect of service offshoring on both profitability and innovativeness of firms and Hijzen et al. (2010) obtained similar results analyzing a panel of Japanese firms.

Our main results are the following ones. The contrasting effects of R\&D and offshoring emerge as determinants of wages. Investment and internal demands are key variables in the realization of profits. When we look at the heterogeneity of the effects we see three main stylized facts. First of all, distinguishing for technological domain using Pavitt classes we can see that rents are effectively related with upgraded industries. Secondly, when we distinguish for the degree of openness we can see that, again, rents are mainly shared in open industries. Finally, when we disentangle the effect on wages per skill level, it is possible to confirm the intuition that offshoring hits the medium low skill categories.

The article is organized as follows. In Section 2 the theoretical framework is presented focusing on wages and profits determination. In Section 3 the database and the adopted methodology are illustrated and some descriptive evidence is shown. Results are presented in Section 5 while Section 6 concludes.

\section{The theoretical framework}

The theoretical setting of our model results from the merge of two different approaches. On the wage determination side, our conceptualization refers to the hypothesis of Van Reenen (1996) regarding 'innovation rents' captured by workers and reflected in wage dynamics. Such 
hypothesis is grounded on the efficiency wage theory (Akerloff and Yellen, 1990). According to the latter, a causal relationship arises between wage level and worker's on-the-job productivity. Employers would like to pay higher wages, above the market-clearing wage, in order to spur the increment in productivity. The basic idea is that worker productivity depends on the wage received, which implies that higher wage represents a higher incentive to be productive for the worker. Furthermore, according to Shapiro and Stiglitz (1984)'s model, an increase in wage decreases a worker's incentive to shirk, boosting worker's productivity and lowering direct monitoring expenses. In this sense, the wage explanation of the 'shirking model' predicts that wage differentials depend on the amount of monitoring costs between different firms and industries. Higher monitoring costs lead to higher wages. On the same ground, wage differentials have been related to firm size by a number of different scholars (Davis and Haltiwanger, 1991; Main and Reilly, 1993; Brunello and Colussi, 1998; Arai, 2003; Lallemand et al., 2005) and more recently by Bottazzi and Grazzi (2010).

The rent sharing hypothesis on which our model is based focuses on the economic rents enjoyed by firms using advanced technology equipment. Wages might be higher in plants applying this equipment because workers are able to capture some of the rents associated with the use of these machines or with the introduction of innovation (Dunne and Schmitz, 1995 and Van Reenen, 1996).

Innovative rents are defined in a Schumpeterian sense and they are intended to be derived from the greater remuneration for the first selling of a new product (Schumpeter, 1942). Van Reenen (1996) identifies three fundamental reasons why large portions of the innovation rents are considered legitimately accessible by workers: i) the time lag between input, R\&D activities, and output of innovation; ii) the difference in time horizon between workers and shareholders, shorter for the former due to the diffusion of temporary contracts; iii) the elements of randomness in the nature of innovation.

Our theoretical specification of wage determinants follows the extension of the innovation rent hypothesis as formulated by Bogliacino (2014). We adapt such model of wage determination originally built to study the relation between technical change and firms' labour demand - to identify the simultaneous role and the interplay of technical change and offshoring in shaping wage dynamics.

Our objective is to disentangle the effects of offshoring and technical change on both the distributive components of income, taking contemporaneously into account the social conflict. With this respect, we combine our wage equation with a Kaleckian profit equation as outlined in sections 2.1 and 2.2. The profit equation accounts for the role of demand and the effect of social conflict. The impact that the variation of wages has on profits is determined, in an indirect way, by the contrasting effect and the interaction of technical change and offshoring of production. 
In order to deepen the effects of industries and countries' heterogeneity we provide a set of tests of our model accounting for: technological heterogeneity at the industry-level, relying on the revised Pavitt taxonomy (Bogliacino and Pianta, 2015); differences in countries and sectors' degree of openness and offshoring propensity, using the industries' grouping resulted from the cluster analysis described in the appendix (Appendix A.2); and, finally, we test our model distinguishing workers' wages by skill. We inquire how the conflictual dynamic between profits and wages as well as the role of technical change and offshoring is reshaped by workers' skill levels. In this sense, we aim to verify the ability of high skill workers to gain more form the sharing of 'innovation rents' and to resist the negative effects of offshoring.

\subsection{The wage equation}

The wage equation is a standard log linear specification augmented with a term for surplus sharing. Since technology and organization of production affects both rents creation and distribution, in principle, this can be captured by a non-linear expression.

$$
\log \left(W_{i t}\right)=\alpha_{0}+\alpha_{1} \log \left(L_{i t}\right)+\alpha_{2} \log \left(Y_{i t}\right)+\Phi\left(\log \left(O F F_{i t}\right), \log \left(R \& D_{i t}\right)\right)+\epsilon_{i t}
$$

where subscript $\mathrm{i}$ and $\mathrm{t}$ indicate respectively the industry-country couple and the time of the observation; w stands for wage, $\mathrm{L}$ for employment, $\mathrm{Y}$ for total output and finally R\&D and OFF represent $\mathrm{R} \& \mathrm{D}$ and offshoring.

The $\Phi$ function is a non-linear form capturing the effects of technology and organization of production.

This wage equation can be seen as an extension of Bogliacino (2014)'s specification. In that work the relationship between technical change and labour demand is explained at the firm level considering 'innovation rents' in the spirit of Van Reenen (1996). Using firms' R\&D expenditure as a proxy for innovation, Bogliacino (2014) suggests the existence of a non-linear relationship between technical change and labour demand. Such nonlinearities are determined by both a scale effect - related to the decreasing returns to scale of $R \& D$ investments due to fixed factors - and a size effect - connected to the fact that larger firms can exploit greater benefits from research activities. 
We extend such framework including the presence of offshoring activities, which could affect wage dynamics in a direct way and through technical change. The non-linearity holds also for the effect of offshoring on wages. ${ }^{3}$

The basic assumption is that production and factors utilization decisions are taken simultaneously, while of course realization of the sales is taking place sequentially.

In Section 3.2 we show that it is possible to Taylor expand the expression in (1), deriving our specification of wage determinants, at the industry level, as in the following expression:

$$
\begin{gathered}
\log \left(W_{i t}\right)=\alpha_{1} \log \left(L_{i t}\right)+\alpha_{2} \log \left(Y_{i t}\right)+\alpha_{3} \log \left(R \& D_{i t}\right)+\alpha_{4} \log \left(O F F_{i t}\right)+\alpha_{5} \log ^{2}\left(R \& D_{i t}\right) \\
+\alpha_{6} \log \left(R \& D_{i t} * O F F_{i t}\right)+\alpha_{7} \log ^{2}\left(O F F_{i t}\right) \\
+u_{i}+e_{i t}
\end{gathered}
$$

Differentiating (2) to get rid of the fixed effects $u_{i}$, we finally obtain our empirical specification of the wage equation (3):

$$
\begin{gathered}
\Delta \log \left(W_{i t}\right)=\alpha_{1} \Delta \log \left(L_{i t}\right)+\alpha_{2} \Delta \log \left(Y_{i t}\right)+\alpha_{3} \Delta \log \left(R \& D_{i t}\right)+\alpha_{4} \Delta \log \left(O F F_{i t}\right) \\
+\alpha_{5} \Delta \log ^{2}\left(R \& D_{i t}\right)+\alpha_{6} \Delta \log \left(R \& D_{i t} * O F F_{i t}\right)+ \\
\alpha_{7} \Delta \log ^{2}\left(O F F_{i t}\right)+\Delta e_{i t}
\end{gathered}
$$

According to equation (3), wages are driven by: the level of economic activity at the sectoral level (which is determined by the firm), the opportunity of capturing innovation rents which could also have non-linear effects; offshoring activities, which could negatively affect wages due to the 'threat effect' on workers' bargaining power and by the interaction between R\&D and offshoring activities of firms. ${ }^{4}$ The latter interaction term could be able to capture firms' strategy (namely, technological versus cost competitiveness strategies).

We expect that firms' R\&D efforts have a positive effect on wage dynamics according to the 'innovation rent capture' hypothesis (Van Reenen, 1996). The offshoring variables would affect negatively wages due to the weakening effect on workers' bargaining power. Nevertheless, the latter effect could vary according to the technological characteristics of industries. ${ }^{5}$ The

\footnotetext{
${ }^{3}$ In Bogliacino (2014) it is shown that at firm level it is possible to obtain this formulation as a structural equation for labour demand at the firm level in the context of a patent race model à la Dasgupta and Stiglitz (1980).

${ }^{4}$ In line with Kramarz (2008), we hypothesize that offshoring can affect wages by altering the firm's threat point and, thus, changing the overall rent shared by firms and workers. In other words, firms willing to reduce union strength use offshoring as an instrument to discipline workers.

${ }^{5}$ The more recent empirical evidence concerning the impact of offshoring on wages is mixed. Some contribution as Fosse and Maitra (2012) found that offshoring as a general positive effect on wages
} 
interaction term between R\&D and offshoring activities could be different in terms of sign and significance due to the prevalence of one of the two effects.

Moreover, the magnitude and the direction of innovation and offshoring on wages could also differ according to workers' skill categories. We expect that high skilled workers are more likely to capture relatively higher shares of the 'innovation rents' compared to medium and low skill ones. Even in the case of offshoring, we expect that the negative effect of the latter on wages is more prominent for low and medium skilled workers.

Finally, grouping different industries in terms of technological intensity and degree of openness could bring to divergent results in terms of intensity and direction of the relationships. The workers operating in high tech industries - identified using the Revised Pavitt taxonomy for manufacturing and services (Bogliacino and Pianta, 2015) - are expected to gain more from innovation and to lose less from offshoring of production. Concerning the degree of openness of industries, we expect that the impact of offshoring and its interaction with innovation is relevant only in the offshoring intensive sectors.

\subsection{The profit equation}

As we anticipate, the profits equation is sequential with respect to wages, since actual profits depend on potential profits (surplus) realized through demand. In our formulation, we provide an extension of Kalecki (1939) in which, exploiting input-output matrices, we disaggregated different source of demand.

Again using logarithms, we obtain the empirical specification of industries' profits as follows:

$$
\log \left(P_{i t}\right)=\alpha_{0}+\alpha_{1} \log \left(I_{i t}\right)+\alpha_{2} \log \left(C_{i t}\right)+\alpha_{3} \log \left(E X P_{i t}\right)-\alpha_{4} \log \left(W_{i t}\right)+u_{i}+\varepsilon_{i t}
$$

where subscript $\mathrm{i}$ and $\mathrm{t}$ indicate respectively the industry-country couple and the time of the observation; w stands for wage, EXP for export, $\mathrm{C}$ for consumption demand and finally I for investment.

Differencing (4) to get rid of the fixed effects $u_{i}$, finally we have:

$$
\Delta \log \left(P_{i t}\right)=\alpha_{1} \Delta \log \left(I_{i t}\right)+\alpha_{2} \Delta \log \left(C_{i t}\right)+\alpha_{3} \Delta \log \left(E X P_{i t}\right)-\alpha_{4} \Delta \log \left(W_{i t}\right)+\varepsilon_{i t}
$$

through both a composition effect - increase in the employed share of high skilled workers - and a rent sharing effect - treating offshoring as a 'rent generating' innovation. Other authors as Hummels et al. (2014), have identified an heterogeneous effect of offshoring according to skills: offshoring tends to increase the high-skilled wage and decrease the low-skilled wage. 
Where, the variable capturing wage variation is the one estimated in (3). With this specification we are able to describe in a detailed way the dynamics and the determinants of income distribution taking into account a variety of features. ${ }^{6}$ We go beyond the explicit identification of the role of social conflict, identifying the supply and demand side factors able to shape such conflict in direction and magnitude. We expect investment and demand having a positive effect on profits variation. Wages will, on the contrary, have a negative impact on profits. Nevertheless, the strength and the significance of this negative effect could be softened or reshaped by the industries' technological characteristics. In the same way, accounting for industries' heterogeneity in their degree of openness could bring to different results considering the different weight that demand for export, innovation and offshoring activities have in different sectors.

\section{Data and methodology}

\subsection{The SID database}

The database used in this paper is the Sectoral Innovation Database (SID) developed at the University of Urbino (Pianta et al., 2011). The database is the result of a merge between different sources of data. For innovation variables - R\&D expenditure, share of firms developing product innovations, expenditure for machineries - data are drawn from four European Community Innovation Surveys - CIS 2 (1994-1996), CIS 3 (1998-2000), CIS 4 (2002-2004) and CIS 6 (2008-2010) - matched with data at the industry level from the WIOD Nace Rev. 1 database ${ }^{7}$.

For production and demand variables - wages, profits, demand and total employees we used data drawn from the World Input Output Database (WIOD) (Timmer et al., 2013). All the data have been converted in euros and in constant prices. Data are available for the two-digit NACE classification for 20 manufacturing and 17 service sectors; all data refer to the total activities of industries. $^{8}$

\footnotetext{
${ }^{6}$ An analogous specification of demand-driven profits has been proposed in Bogliacino and Pianta (2013a).

${ }^{7}$ In order to allow comparability, innovation variables drawn from CIS6 have been converted in Nace Rev.1 through the conversion matrix introduced by Perani and Cirillo (2015).

${ }^{8}$ In line with previous empirical literature analyzing the impact of offshoring, we excluded from our analysis the (Nace Rev.1) sector 23 (Mineral oil refining, coke \& nuclear fuel). Previous analyses performed using WIOD and SID data showed that results were quite sensitive to the inclusion of this particular industry. In particular, sector 23 stands out in many respects, for instance, in terms of a very high degree of vertical specialisation, the high energy intensity, extremely high labour productivities, excessive capital coefficients, etc. Hence, this industry is excluded to avoid distorted results. (Foster et al., 2012; Landesmann and Leitner, 2015).
} 
The use of Input-Output tables is aimed at disentangling the production structure, relating domestic and imported inputs and industries (Yamano and Ahmad, 2006 and Timmer et al., 2013). Indicators are computed as the sum of the expenditure devoted by each industry to the acquisition of different types of inputs, all divided by the total production output of each user sector (Feenstra and Hanson, 1996).

The country coverage of the database includes five major European countries - Germany, France, Italy, Spain, and United Kingdom - that represent a large part of the European economy. ${ }^{9}$ The selection of countries and sectors has been made in order to avoid limitations in access to data (due to the low number of firms in a given sector of a given country, or to the policies on data released by National Statistical Institutes).

The time structure of the panel is the following. Economic and demand variables are calculated for the periods 1996-2000, 2000-2003, 2003-2007 and 2007-2010. Innovation variables refer to 1994-1996 (linked to the first period of economic variables); 1998-2000 (linked to the second period of economic variables); 2002-2004 (linked to the third period of economic variables) and 2006-2008 (linked to the fourth period of economic variables). The variables used are listed in Table 1.

Table 1. List of Variables

\begin{tabular}{lcc}
\hline Variable & \multicolumn{1}{c}{ Unit } & Source \\
\hline In-house R\&D exp. per employee & Thousands euros/empl & SID - (CIS Var.) \\
New machinery exp. per employee & Thousands euros/empl & SID - (CIS Var.) \\
Rate of gr. of Exports & Annual rate of growth & SID - (WIOD I-O Var.) \\
$\begin{array}{l}\text { Rate of gr. of Intermediate } \\
\text { Demand }\end{array}$ & Annual rate of growth & SID - (WIOD I-O Var.) \\
$\begin{array}{l}\text { Rate of gr. of Final Demand } \\
\text { Rate of gr. of Offshoring (F \&H }\end{array}$ & Annual rate of growth & SID - (WIOD I-O Var.) \\
Nar.) & Simple difference & SID - (WIOD I-O Var.) \\
Rate of gr. of Wages & Annual rate of growth & SID - (WIOD I-O Var.) \\
Rate of gr. of Profits & Annual rate of growth & SID - (WIOD I-O Var.) \\
\hline
\end{tabular}

Source: Sectoral Innovation Database (Pianta et al., 2011). Note: Rate of growth are compound annual rate of growth computed over four and three years periods (1996-2000; 2000-2003; 2003-2007; 2007-2010). The rate of growth of wages is computed for the industries' aggregate and divided by skill (High, Medium and Low skill) according to the ISCED classification.

Economic variables are deflated using the sectoral Value Added deflator from WIOD (base year 2000), corrected for PPP (using the index provided in Stapel et al. 2004). For the performance

\footnotetext{
${ }^{9}$ The economies considered in our analysis (GER, ES, FR, IT and UK) account for the $71 \%$ of the whole EU28 GDP. Data are reported by Eurostat for the year 2014 (http://appsso.eurostat.ec.europa.eu).
} 
variable we compute the compound annual growth rate that approximates the difference in log; for innovation we use the shares of firms in the sector or expenditure per employee; this can be justified considering innovative efforts as dynamic and capturing the change in the technological opportunities available to the industry. Wage variables are expressed per worked hours (hourly wage). We use a narrow definition of international outsourcing which only considers imported intermediates in a given industry from the same industry (which corresponds to diagonal terms of the import-use matrix). Feenstra and Hanson (1996) refer to this measure as narrow offshoring ${ }^{10}$ (FHN). The formal expression of the FHN indicator is the following:

$$
\text { OFFSH } H_{i, j, t}^{F H N}=\frac{\text { Imported_Int_Inputs }_{i, k \neq j, t}}{\text { Total_Int_Inputs } s_{i, j, t}}
$$

where, $\mathrm{i}$ stands for the industry, $\mathrm{j}$ for country and $\mathrm{t}$ for time. Some further test using the FHN and other offshoring indicators - namely, the broad offshoring extensions proposed in Guarascio et al. (2014 and 2015) where inflowing intermediate inputs are discriminated according to their technological intensity - are provided in the Appendix. ${ }^{11}$

The dataset is a panel over four periods covering a time span from 1995 to 2010 across five major European countries.

\subsection{Descriptive statistics}

The following Section provides a descriptive evidence of the main variables and relationships investigated in this work. Table 2 reports the main descriptive statistics for our key variables computed over the whole sample of industries. Tables 3 and 4 report the same statistics considering different clusters of industries. First, we distinguish the industries according to their technological intensity. Using the Revised Pavitt Taxonomy (Bogliacino and Pianta, 2015), we define High Tech industries those sectors belonging to Science Based and Specialized Suppliers clusters; while Low Tech industries are those belonging to Scale Intensive and Supplier Dominated ones.

\footnotetext{
${ }^{10}$ Among various measures of offshoring - built using intermediate inputs flows - Feenstra and Hanson (1999) emphasize the reliability of the narrow definition as it is thought to be closer to the essence of fragmentation, which necessarily takes place within the industry.

11 The choice of the narrow offshoring indicator is in line with the existing empirical literature and doesn't introduce biases in our estimations when we operate the clustering according to the industries' offshoring intensity (Guarascio et al., 2014 and 2015). In the Appendix (A.2) we report the correlation coefficients of the FHN with a set of different offshoring indicators computed over the considered sample of European industries.
} 
Table 2. Descriptive statistics

Compound average annual rate of variation, whole sample (DE, IT, ES, FR, UK, 1995-2010)

\begin{tabular}{lll}
\hline Variable & Statistics & Whole sample \\
\hline Wages (\%) & Mean & 2.35 \\
Profits (\%) & Std. Dev. & 3.18 \\
& Mean & 2.51 \\
R\&D per employee & Std. Dev. & 2.05 \\
& Mean & 2.63 \\
New Mach. per employee & Std. Dev. & 4.86 \\
& Mean & 1.63 \\
Narrow Offshoring & Std. Dev. & 2.27 \\
& Mean & 0.07 \\
& Std. Dev. & 0.07
\end{tabular}

Source: Sectoral Innovation Database (Pianta et al., 2011). Note: Wages are sectoral wages per worked hours, Profits are the sectoral aggregated gross operating surplus. R\&D expenditure and Expenditure for new machineries are expressed in thousands of euros for employee. All the variables are in euros and in real terms

Table 3. Descriptive statistics by technological intensity of industries Compound average annual rate of variation, whole sample (DE, IT, ES, FR, UK, 1995-2010)

\begin{tabular}{llll}
\hline Variable & & High Tech cluster & Low Tech cluster \\
\hline Wages (\%) & Mean & 2.95 & 2.02 \\
\multirow{2}{*}{ Profits (\%) } & Std. Dev. & 3.54 & 2.92 \\
\multirow{2}{*}{ R\&D per employee } & Mean & 1.55 & 3.03 \\
& Std. Dev. & 1.16 & 1.34 \\
\multirow{2}{*}{ New Mach. per employee } & Mean & 5.83 & 0.96 \\
& Std. Dev. & 7.20 & 2.10 \\
\multirow{2}{*}{ Narrow Offshoring } & Std. Dev. & 1.73 & 1.58 \\
& Mean & 2.13 & 2.35 \\
& Std. Dev. & 0.10 & 0.06 \\
\hline
\end{tabular}

Source: Sectoral Innovation Database (Pianta et al., 2011). Note: Technological clusters are made cording to the Revised Pavitt Taxonomy: High Tech industries: SB=Science Based, SS=Supplier Specialized; Low Tech industries: $\mathrm{SI}=$ Scale Intensive, $\mathrm{SD}=$ Supplier Dominated.

The evidence presented in Table 3 confirms the presence of heterogeneity once considered industries' technological intensity. The rate of change of hourly wages is relatively higher in High Tech clusters with respect to both the whole sample average (Table 2) and the Low Tech ones; on the contrary, the rate of change of operating surplus is higher in Low Tech industries, 
even if with a great variability. As expected, R\&D efforts are sensibly higher in High Tech sectors compared to the sample mean and to the intensity observed in Low Tech industries. Also in this case, we register a relatively large dispersion of $R \& D$ around the mean, mostly in High Tech industries suggesting the existence of major differences in $R \& D$ expenditure even in the same group of High Tech industries. The same holds for the variable capturing expenditure for new machineries and equipment, even if to a lower extent. This preliminary evidence seems to support the thesis of a tendency towards relatively higher wages in industries characterized by higher innovation. In fact, the higher rate of growth of profits in low tech sectors compared to high tech ones could reflect the greater ability of workers in extracting 'innovation rents' in the former group of industries.

Finally, the intensity of offshoring activities seems to be higher in High Tech industries showing a stronger international dynamism of knowledge intensive sectors. Table 4 reports the descriptive evidence with the industries clustered according to their degree of openness. The clustering has been performed following standard techniques, and the technical details are reported in Appendix A1. In line with previous results (Bogliacino and Pianta, 2013b; Guarascio et al., 2015), industries relatively more open to international trade and involved in Global Value Chains (GVC) show the higher rate of growth of both profits and wages.

Table 4. Descriptive statistics by openness degree of industries Compound average annual rate of variation (DE, IT, ES, FR, UK, 1995-2010)

\begin{tabular}{llll}
\hline Variable & & Open cluster & Closed cluster \\
\hline Wages (\%) & Mean & 4.10 & 1.82 \\
Profits (\%) & Std. Dev. & 3.53 & 2.86 \\
\multirow{3}{*}{ R\&D per employee } & Mean & 2.91 & 2.40 \\
& Std. Dev. & 2.06 & 1.90 \\
New Mach. per employee & Mean & 6.38 & 1.18 \\
\multirow{3}{*}{ Narrow Offshoring } & Std. Dev. & 7.20 & 2.11 \\
& Mean & 2.24 & 1.39 \\
& Std. Dev. & 2.42 & 2.17 \\
& Mean & 0.19 & 0.04 \\
\hline
\end{tabular}

Source: Sectoral Innovation Database (Pianta et al., 2011).

Such evidence could be partly explained by the higher level of R\&D intensity detected for the open cluster of industries. As expected, the average value of the offshoring intensity is higher for the Open cluster compared the Closed one as well as to the whole sample average.

Tables 3 and 4 point out potential sources of heterogeneity. Therefore, we implement our model considering different sub-groups - High versus Low Tech and Open versus Closed clusters of 
industries. Section 3.2 sketches some basic pieces of evidence regarding our theoretical framework.

\subsection{Some preliminary analysis}

In Figures 1 and 2, we show the annual wage rate of growth of sectors according to the intensity of offshoring performed. Sectors have been divided in two groups considering as a threshold the annual median of the discriminant variable.

Figure 1. Mean annual rate of change of wages by intensity of offshoring and R\&D

(1996-2000; 2000-2003; 2003-2007; 2007-2010)
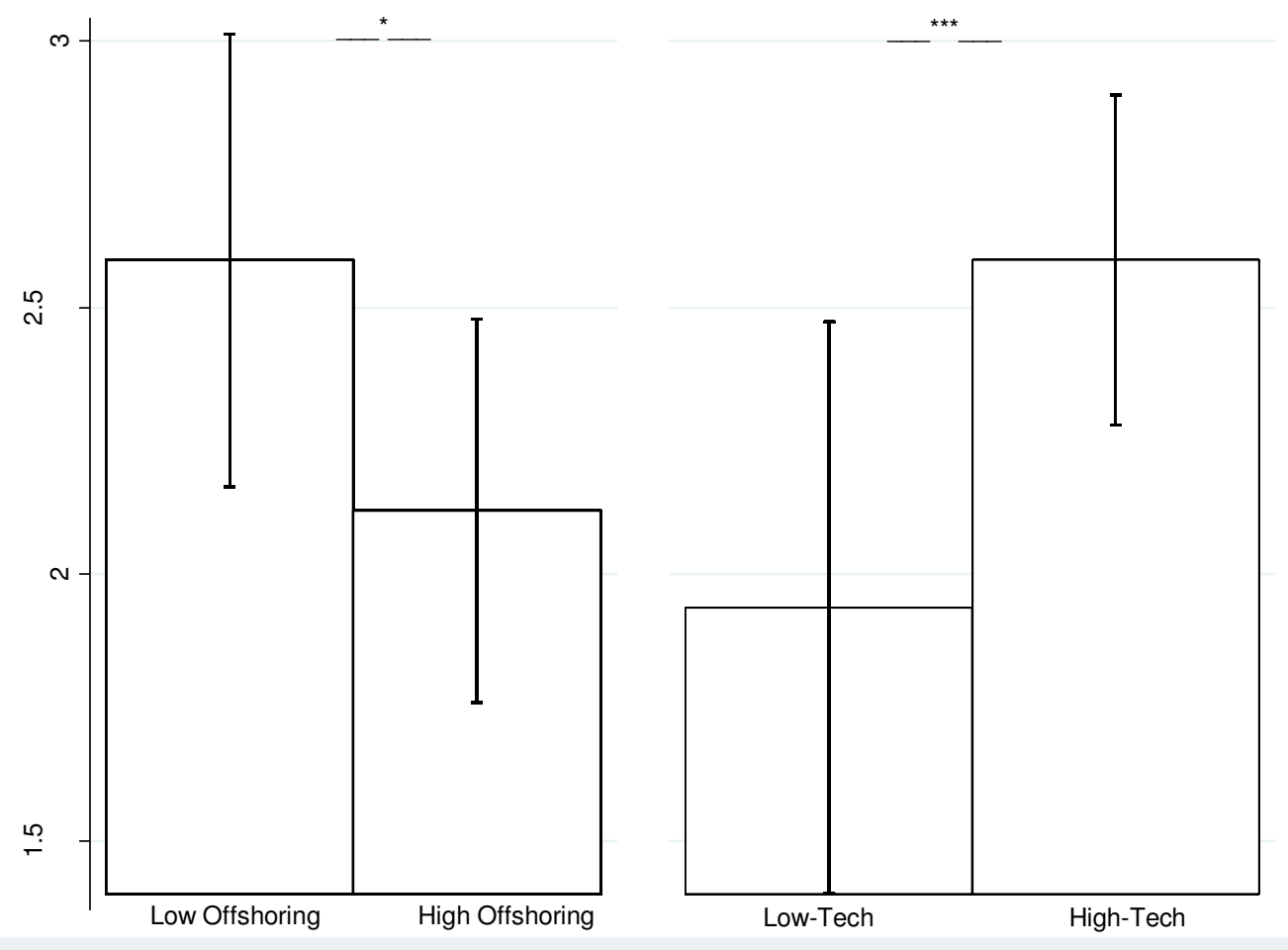

Source: Sectoral Innovation Database (Pianta et al., 2011). Confidence interval at 95\%. Stars refer to Wilcoxon rank sum test, ${ }^{*}$ significant at $10 \%,{ }^{* *}$ significant at $5 \%,{ }^{* * *}$ significant at $1 \%$.

The 'high offshoring' group comprehends all sectors registering an above-the median value of FHN offshoring index (6); conversely, low offshoring sectors are those characterized by a below the median offshoring activity. The median criterion has been applied also for high-tech and low-tech sectors, where the first ones register an above the median expenditure in $R \& D$ and the second ones a below-the median level of R\&D.

We report also the result of a Wilcoxon rank-sum test, to see if the split is associated to statistically significant differences in the distribution of wage growth. As Figure 1 shows, a high level of offshoring is associated with lower wage growth compared to those sectors 
characterized by relatively lower offshoring intensity. As expected, at aggregate level, a major degree of openness - proxied by the offshoring intensity - pushes downward wages. Conversely and according to our framework, technology pushes upward wages because workers could take part to the extra-rents gained at the industry level after the introduction of new products. High Tech sectors are characterized by higher wage growth. Differences are statistically significant, as shown by the rank-sum test performed.

Figure 2. Mean annual rate of change of wages by intensity of offshoring and skill group (1996-2000; 2000-2003; 2003-2007; 2007-2010)

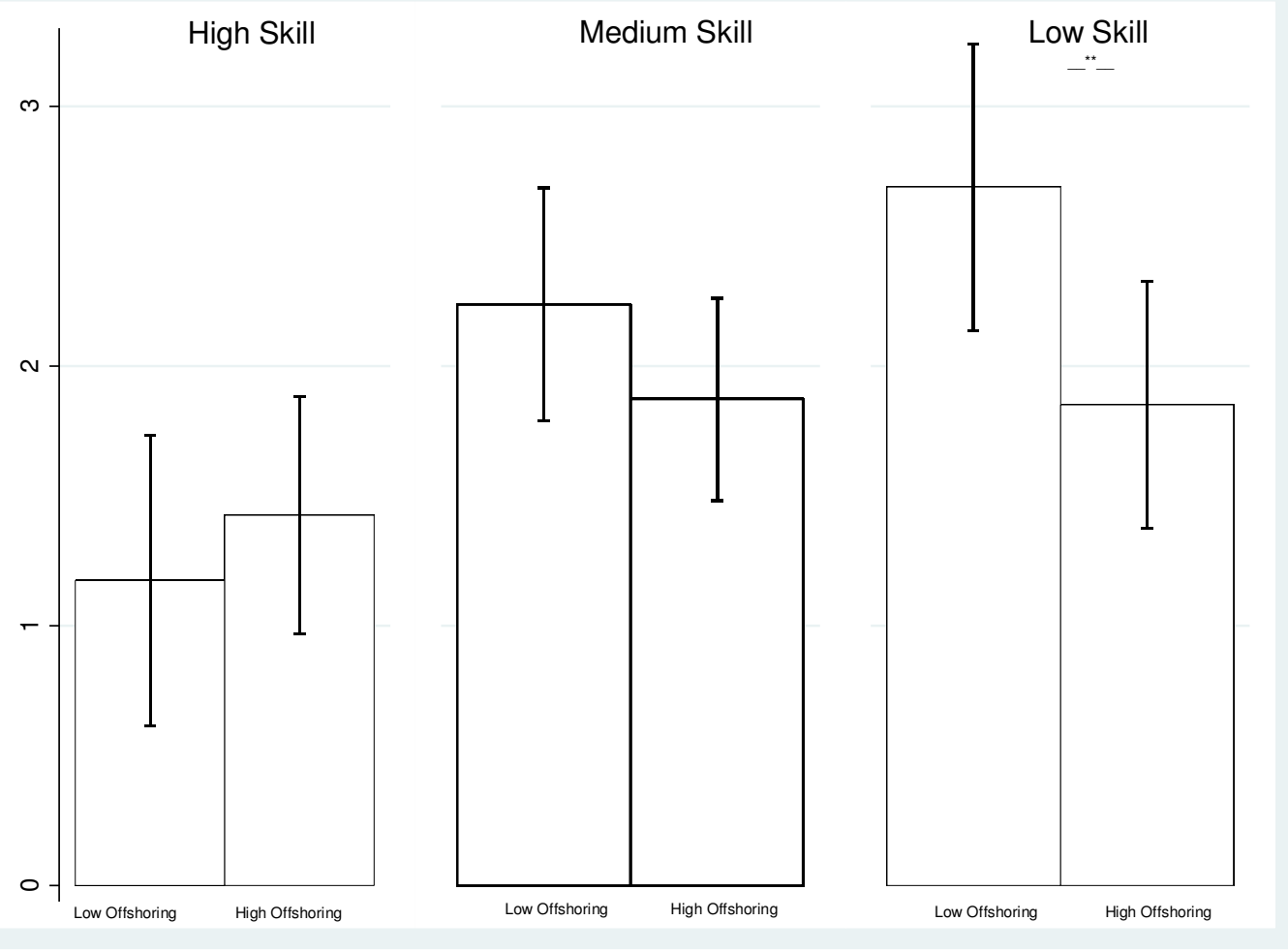

Source: Sectoral Innovation Database (Pianta et al., 2011). Confidence intervals at 95\%. Stars refer to Wilcoxon rank sum test, ${ }^{*}$ significant at $10 \%,{ }^{* *}$ significant at $5 \%,{ }^{* * *}$ significant at $1 \%$.

Figure 3. Mean annual rate of change of wages by intensity of $R \& D$ and skill group (1996-2000; 2000-2003; 2003-2007; 2007-2010) 


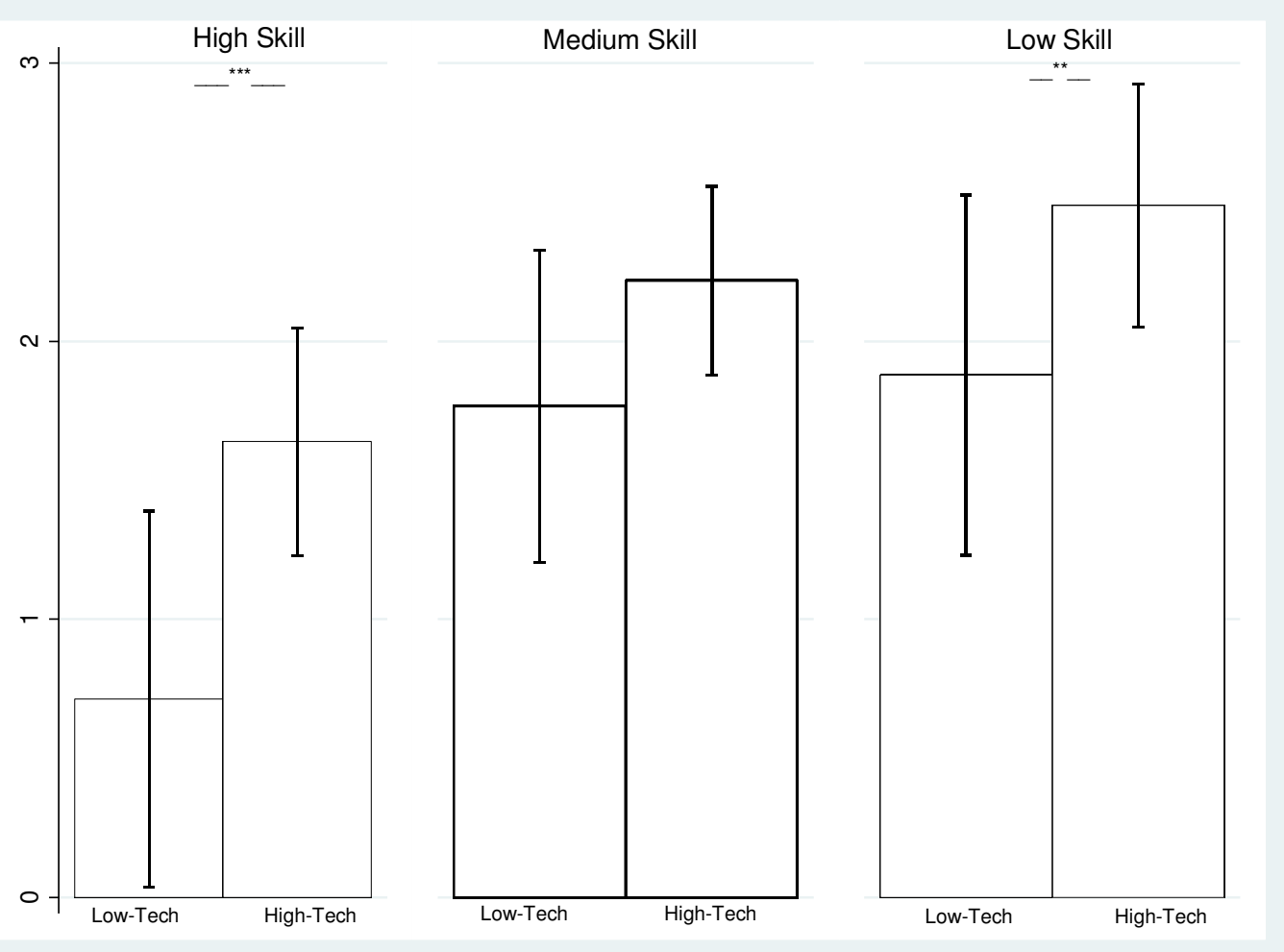

Source: Sectoral Innovation Database (Pianta et al., 2011). Confidence intervals at 95\%. Stars refer to Wilcoxon rank sum test, ${ }^{*}$ significant at $10 \%,{ }^{* *}$ significant at $5 \%,{ }^{* * *}$ significant at $1 \%$.

In Figure 2 and 3 we have further evidence on the impact over different categories of skills. The aggregate pattern is confirmed, although with less robust evidence. As expected, offshoring puts downward pressure on wages for low skilled workers (figure 2). On the contrary, all skill groups experience the technology wage premium, although the distribution is statistically different only for high and low skill categories. Overall, while offshoring push downward wages, technology exercises an opposite force pushing upward wages mostly for high and low skill categories. In the empirical investigation, we try to disentangle how both forces, offshoring and technology, interact together on wages. It is clear that while there is a clear cut 'class conflict' between capital and labour, the picture is more nuanced when we separate by skill, essentially because there is also horizontal bargaining power difference across groups of workers.

Turning to profits dynamics (Figure 4), it clearly emerges how profits growth is related to demand, external, internal, and investments. Those sectors characterized by sustained demand growth experience profits growth since actual profits depend on potential profits (surplus) realized through demand. Again, the distributions are statistically different has shown by the rank sum test reported on top of the graphs.

Figure 4. Mean annual rate of change of profits by typology of demand - internal, external, investments (1996-2000; 2000-2003; 2003-2007; 2007-2010) 


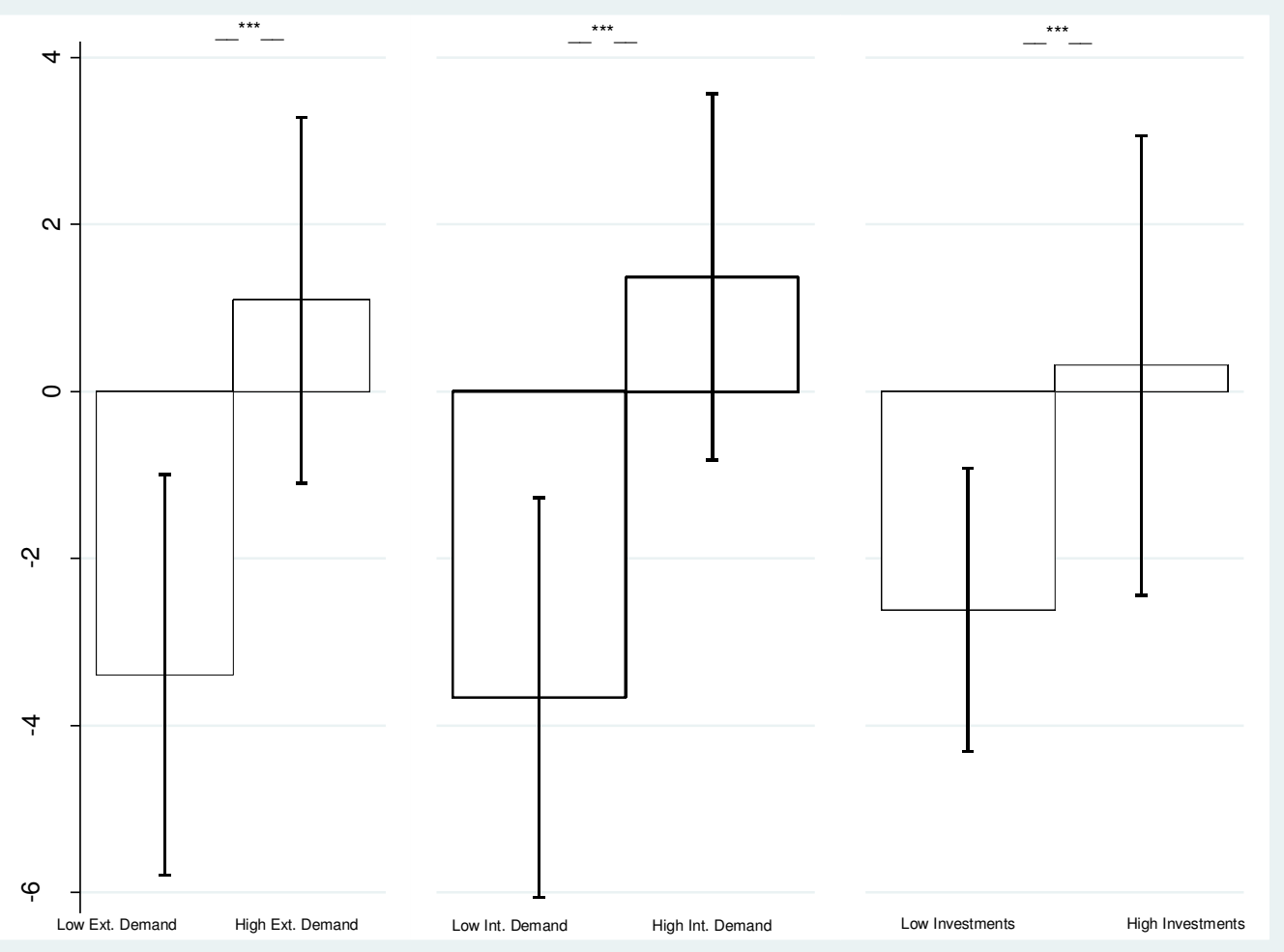

Source: Sectoral Innovation Database (Pianta et al., 2011). Confidence intervals at 95\%. Stars refer to Wilcoxon rank sum test, ${ }^{*}$ significant at $10 \%,{ }^{* *}$ significant at $5 \%,{ }^{* * *}$ significant at $1 \%$.

Among the three main components of demand, internal demand seems to be the major driver of profits growth.

\subsection{Econometric strategy}

We consider the following specification. Since we are interested in structural interpretation we estimate the two equations (7) separately:

$$
\begin{gathered}
w_{i t}=\Phi\left(X_{i t}\right)+Z_{i t} \beta+\varepsilon_{i t} \\
\pi_{i t}=\alpha w_{i t}+R_{i t} \gamma+\omega_{i t}
\end{gathered}
$$

where $\left(X_{i t} ; Z_{i t}\right)$ and $\left(w_{i t} ; R_{i t}\right)$ are matrices whose columns are covariates, and $\left(\varepsilon_{i t} ; \omega_{i t}\right)$ is a nT times two matrix with the random errors. Let's consider the wage equation first. To identify the effects of the covariates under OLS we would require strong exogeneity, i.e. exogeneity with respect to the random terms and absence of feedback from the $\varepsilon_{i t}$ to the $\left(X_{i t} ; Z_{i t}\right)$. To soften this problem, we first calculate first differences. First of all, this operation removes the time invariant part. Secondly, under first difference specification, identification requires that the regressors be orthogonal to the innovation in the random errors term. In other words, they should be predetermined, eliminating the no feedback requirement. 
To capture the effect of R\&D and offshoring we must expand the phi function, using a Taylor approximation. If we take a $\log$ formulation as usual, we can write as follows (8):

$$
\begin{aligned}
& \log (z y)=\log ((0,0))+\frac{{ }_{1}(0,0)}{(0,0)} x+\frac{{ }_{12}(0,0)}{(0,0)} y+\left({ }^{2}(0,0){ }_{1}^{2}(0,0)+{ }^{1}(0,0) \quad{ }_{11}(0,0)\right) x^{2}+ \\
& 2\left({ }^{2}(0,0){ }_{1}(0,0) \quad{ }_{2}(0,0)+{ }^{1}(0,0) \quad{ }_{12}(0,0)\right) x y+\left({ }^{2}(0,0) \quad{ }_{2}^{2}(0,0)+\quad{ }^{1}(0,0) \quad{ }_{22}(0,0)\right) y^{2}+ \\
& +\operatorname{to}|(x, Z)|^{2}
\end{aligned}
$$

where $\mathrm{z}$ and $\mathrm{y}$ are respectively the $\mathrm{R} \& \mathrm{D}$ and the Offshoring variable in log terms.

By taking the first difference, we can apply the operator to expression (8) as well. Nevertheless, the regressors are still contemporaneous to the innovation. However, we can take long differences to weaken this endogeneity problem, in this case we take the log variation over a large time span. Finally, since log variations are approximations to the rate of change, we can multiply the long difference equation by $1 / \mathrm{n}$ where $\mathrm{n}$ is the number of years covered by the long difference. As a result, we can directly use average rate of variation over the period. A similar procedure is used for the profit equation, where the linear expression does not require Taylor expansion. Estimation is done in two steps according to our theoretical formulation.

\section{Results}

\subsection{Main Results}

In this section we provide the results of the empirical analysis conducted on our panel of European industries. ${ }^{12}$ The structure of the section is the following: first, the outcome of the estimations of wages and profits for the whole sample of industries are reported (Table 5); second, we present the same estimations implemented dividing our sample according to industries' technological intensity and degree of openness (Tables 6 and 7); finally, the outcome of the model broken down by skill categories (high, medium and low skill according to the ISCED classification) is shown ${ }^{13}$ (Tables 8,9 and 10).

\footnotetext{
${ }^{12}$ In the estimations we used as dependent variables the variation of total sectoral profits and the one of wages per worked hours. While a more specific investigation of rates of return per capital could be more appropriate, the lack of data on industries' capital fixed assets makes such analysis unfeasible. However, under the assumption that capital stock doesn't change rapidly at the industry level, is reasonable to assume that the variation of total profits works as a good returns to capital proxy. On the contrary, the total wage bill directly depends on the number of hours worked. Therefore, to properly identify the relationship between labor remuneration profits, innovation and offshoring such wage representation is considered a more appropriate measure (Pianta and Tancioni, 2008).

${ }^{13}$ In order to exclude any risk of biases in the results, we have tested the baseline model (table 5) excluding observations belonging to the last period of crisis (2007-2010). All the identified relationships - with the exception of investments in the profits equation, which are no longer significant when the crisis period is excluded - were found to be robust to such validation procedure.
} 
As argued above, our identification strategy is based on the sequential nature of wage setting and profits realization process. Therefore, we estimated a Two Stages Least Square model (2SLS) regressing, in the first step, the wage equation against technological, offshoring and production variables as explained in Subsection 2.1; in the second step, we estimate the profit equation using as covariate, beside demand components, the wage variable estimated in the first step. In order to control for all possible sources of heterogeneity, each equation is estimated including time, country and sectoral dummies. In the Appendix (A2) a wide set of diagnostic tests has been provided to address multicollinearity, heteroschedasticy and endogeneity issues.

Table 5 shows first and second step estimations. The first column contains the outcome of the wage equation's estimation (first step) highlighting the contrasting role of innovation and offshoring. While product innovation pushes upward wages, an increase in offshoring compresses workers' remuneration. In the second column, the outcome of profits equation estimation (second step) is presented.

The estimation of wage determinants (first column) supports our thesis of an 'innovation rent' partly earned by wages. The coefficient associated to the sectoral R\&D expenditure is positive and strongly significant. As expected, offshoring seems to play an opposite role, having a negative and significant effect on wages. Some non linearity clearly emerges. Innovation, proxied by sectoral $R \& D$ intensity, seems to have a concave effect. Such concavity is captured by the negative and significant coefficient associated to the square of $R \& D$ expenditure per employee. The interaction between offshoring and innovation variables turns out to be not significant in explaining wage dynamics. Both the employment and the gross output variables are significant and in line with our expectations.

Table 5. The Wages-Profits 2SLS estimation (whole sample)

\begin{tabular}{|c|c|c|}
\hline & $\begin{array}{l}\text { (First Step) } \\
\Delta \text { Wages/hour }\end{array}$ & $\begin{array}{l}\text { (Second Step) } \\
\Delta \text { Profits }\end{array}$ \\
\hline R\&D expenditure & $\begin{array}{l}0.31 \\
{[0.05]^{* * *}}\end{array}$ & \\
\hline R\&D expenditure (squared) & $\begin{array}{l}-0.00 \\
{[0.00]^{* *}}\end{array}$ & \\
\hline Narrow Offshoring & $\begin{array}{l}-0.55 \\
{[0.13]^{* * *}}\end{array}$ & \\
\hline Narrow Offshoring (squared) & $\begin{array}{l}0.03 \\
{[0.02]}\end{array}$ & \\
\hline R\&D expenditure * Narrow Offshoring & $\begin{array}{l}-1.65 \\
{[0.01]}\end{array}$ & \\
\hline Employment (Rate of Growth) & $\begin{array}{l}-0.33 \\
{[0.07]^{* * *}}\end{array}$ & \\
\hline Gross Output (Rate of Growth) & $\begin{array}{l}0.38 \\
{[0.05]^{* * *}}\end{array}$ & \\
\hline$\Delta$ Wages/hour & & $\begin{array}{l}-0.64 \\
{[0.34]^{*}}\end{array}$ \\
\hline Expenditure for Mach. \& Equipments & & $\begin{array}{l}0.60 \\
{[0.35]^{*}}\end{array}$ \\
\hline
\end{tabular}




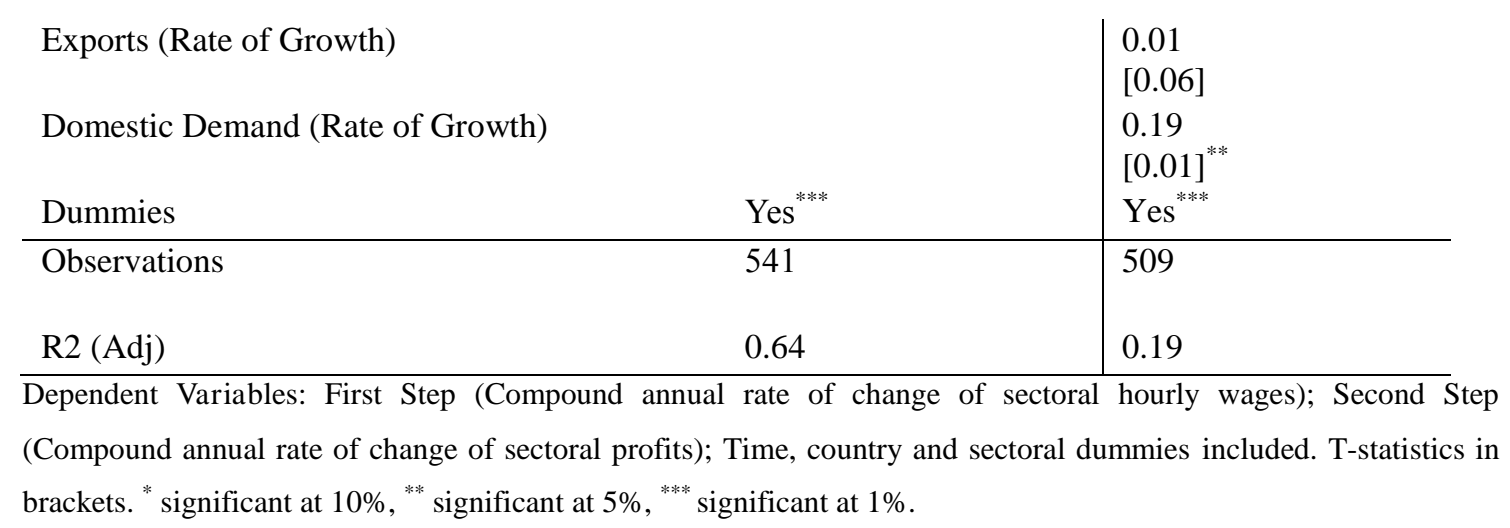

The coefficient associated to the rate of change in employment is negative and significant, signaling the standard neoclassical dynamics of the labour market. On the contrary, an increase in industry's gross output is associated with an increase in wages.

Moving to the profit equation (second column), coefficients' magnitudes, direction and significance level are in line with the theoretical hypothesis presented in Section 2 and with the empirical evidence shown in Section 3. The rate of growth of wages has a negative and significant impact on profits, highlighting the existence of a conflictual dynamic. Coherently with the bargaining mechanism described above, the negative impact of wages is enhanced and softened respectively by: the ability of workers of capture part of the innovation rent (identified by the R\&D variable in the first equation); the weakening of workers' bargaining power due to production's offshoring. The Kaleckian-Keneysian linkage between demand and profits is confirmed by the positive and significant sign of the variable related to the rate of growth of domestic demand. The most dynamic component of demand, exports, turned out to be not significant. The results of the whole sample estimations support the theoretical framework proposed in Section 2, namely the existence of a conflictual dynamic between profits and wages driven by different forces. Remarkably, the contrasting effect of innovation and offshoring clearly emerges from the first step of the estimation.

\subsection{Heterogeneity of the impact}

Table 6 reports the results of the estimation performed grouping industries according to their technological intensity. ${ }^{14}$

\footnotetext{
${ }^{14}$ The validity of the sectors' clustering used for the estimations in Table 6 and 7 - high versus low-tech and open versus closed industries - has been further tested implementing a Chow test. The results of the test are in the Appendix, Tables A7 and A8. The Chow test signals the presence of a structural difference within the data according to specific variables - in our case technological intensity and degree of openness. The values of the F statistic resulting from the Chow test's implementation does not reject the selected clustering.
} 
Table 6. The Wages-Profits 2SLS estimation (High Tech vs Low Tech Sectors)

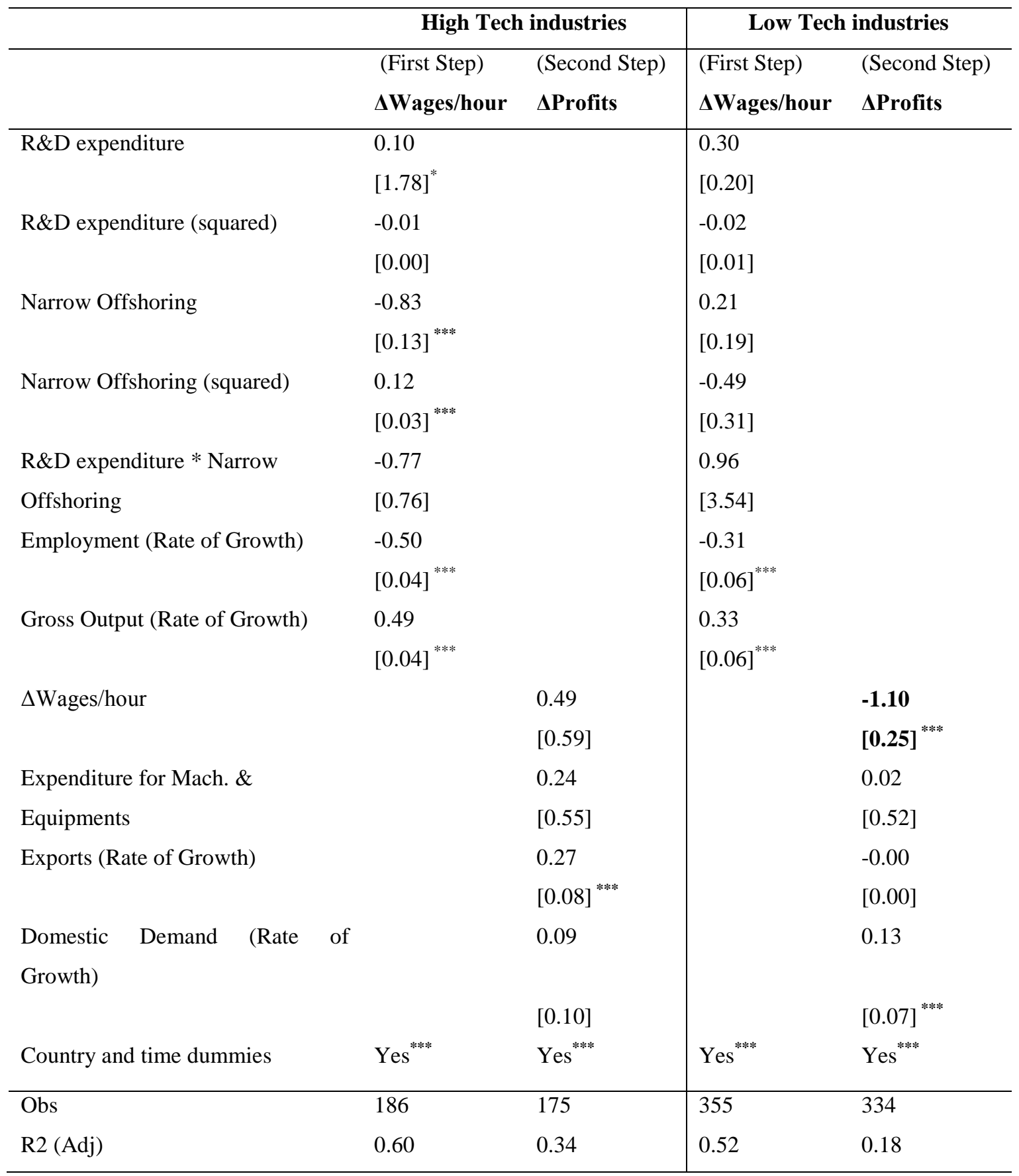

Dependent Variables: First Step (Compound annual rate of change of sectoral hourly wages); Second Step (Compound annual rate of change of sectoral profits); Time and country dummies included. Adjusted Std. errors in brackets. ${ }^{*}$ significant at $10 \%,{ }^{* *}$ significant at $5 \%,{ }^{* * *}$ significant at $1 \%$.

Note: Industries are grouped according to the Revised Pavitt Taxonomy (Bogliacino and Pianta, 2015). High Tech industries are those belonging to the Science Based and Supplier Specialized sectors; Low Tech industries are those belonging to the Scale Intensive and Supplier Dominated sectors.

The first element emerging from the estimation in Table 6 concerns the impact of innovation on wages dynamics. The positive and significant impact of R\&D efforts on wages holds for the 
High Tech cluster of industries while it seems to disappear for the Low Tech group. The compressing role of offshoring on wages is significant for the High Tech cluster losing relevance for Low Tech industries which are poor performers on international markets as shown in the descriptive statistics (Table 3). Even the dynamics of profits is affected by sector's technological intensity. The growth of profits in High Tech sectors is explained exclusively by the growth of exports, underlining the relevance of international demand for knowledge intensive industries. Furthermore, the "class conflict" is softened for the High Tech cluster while it is strong in Low Tech ones. This could be related to the relatively higher rent to be shared in the High Tech industries, which weakens the attrition. As expected, domestic demand growth affects positively wages in the Low Tech cluster. The latter result depicts the greater dependence on domestic market of Low Tech compared to the High Tech sectors. ${ }^{15}$

The outcome of the model estimated distinguishing industries by their degree of openness are reported in Table 7. As already mentioned, the grouping of industries according to their degree of openness is the result of the cluster analysis described in the Appendix (A.1). Sectors included in the 'Open' Group are identified as the more prone to international trade and offshoring activities. Interesting heterogeneity in terms of results emerges also when the distinction between 'Open' and 'Closed' industries is accounted for. Looking at the first step estimation, the positive effect of $R \& D$ on wages is detected only for the Open cluster. This result confirms the similarities in behavior between the knowledge intensive and the more internationally integrated industries. As expected, the contrasting effect of offshoring on wages is there only for the 'Open' cluster.

Table 7. The Wages-Profits 2 SLS estimation ('Open' vs 'Closed' Sectors)

\begin{tabular}{|c|c|c|c|c|}
\hline & \multicolumn{2}{|c|}{ 'Open' industries } & \multicolumn{2}{|c|}{ 'Closed' industries } \\
\hline & (First Step) & (Second Step) & (First Step) & (Second Step) \\
\hline & $\Delta$ Wages/hour & $\Delta$ Profits & $\Delta$ Wages/hour & $\Delta$ Profits \\
\hline \multirow[t]{2}{*}{ R\&D expenditure } & 0.13 & & 0.10 & \\
\hline & {$[0.08]^{*}$} & & {$[0.11]$} & \\
\hline \multirow[t]{2}{*}{ R\&D expenditure (squared) } & -0.00 & & -0.00 & \\
\hline & {$[0.00]$} & & {$[0.00]$} & \\
\hline \multirow[t]{2}{*}{ Narrow Offshoring } & -0.79 & & -1.82 & \\
\hline & {$[0.15]^{* * * *}$} & & {$[25.00]$} & \\
\hline \multirow[t]{2}{*}{ Narrow Offshoring (squared) } & 0.46 & & -0.15 & \\
\hline & {$[0.31]$} & & {$[0.81]^{* * *}$} & \\
\hline R\&D expenditure $*$ Narrow & -0.77 & & -0.10 & \\
\hline Offshoring & {$[-0.76]^{* * *}$} & & {$[0.50]^{* * *}$} & \\
\hline
\end{tabular}

\footnotetext{
${ }^{15}$ Similar results have been obtained by Bogliacino and Pianta (2013a) and Guarascio et al (2014).
} 


\begin{tabular}{|c|c|c|c|c|}
\hline Employment (Rate of Growth) & $\begin{array}{l}-0.57 \\
{[0.06]^{* * *}}\end{array}$ & & \multicolumn{2}{|l|}{$\begin{array}{l}-0.31 \\
{[0.06]^{* * * *}}\end{array}$} \\
\hline Gross Output (Rate of Growth) & $\begin{array}{l}0.55 \\
{[0.06]^{* * *}}\end{array}$ & & $\begin{array}{l}0.33 \\
{[0.06]^{* * * *}}\end{array}$ & \\
\hline$\Delta$ Wages/hour & & $\begin{array}{l}-0.24 \\
{[0.55]}\end{array}$ & & $\begin{array}{l}-0.82 \\
{[0.37]^{* * * *}}\end{array}$ \\
\hline Expenditure for Mach. \& & & 0.77 & & 0.18 \\
\hline Equipments & & {$[0.70]$} & & {$[0.44]$} \\
\hline Exports (Rate of Growth) & & $\begin{array}{l}0.48 \\
{[0.12]^{* * * *}}\end{array}$ & & $\begin{array}{l}-0.00 \\
{[0.00]}\end{array}$ \\
\hline \multirow[t]{2}{*}{$\begin{array}{l}\text { Domestic Demand (Rate of } \\
\text { Growth) }\end{array}$} & & 0.48 & & 0.23 \\
\hline & & {$[0.12]$} & & {$[0.08]^{* * * *}$} \\
\hline Country and time dummies & Yes $^{* * *}$ & Yes $^{* * *}$ & Yes $^{* * *}$ & $\mathrm{Yes}^{* * * *}$ \\
\hline Obs & 155 & 146 & 386 & 363 \\
\hline R2 (Adj) & 0.54 & 0.39 & 0.13 & 0.13 \\
\hline
\end{tabular}

Dependent Variables: First Step (Compound annual rate of change of sectoral hourly wages); Second Step (Compound annual rate of change of sectoral profits); Time, country and sectoral dummies included. Std. errors in brackets. ${ }^{*}$ significant at $10 \%,{ }^{* *}$ significant at $5 \%,{ }^{* * *}$ significant at $1 \%$.

Note: Industries are grouped according to the cluster analysis described in the Appendix (A.1).

Nevertheless, the non-linear effect of offshoring on wages holds only for the 'Closed' cluster suggesting the existence of an upward pressure on wages after a threshold level of offshoring. Differently to what observed before, the interaction between R\&D efforts and offshoring of production has a negative and significant impact on wages in both clusters. This means that in each cluster, the negative effect of offshoring on wages seems to overcome the positive one of $R \& D$, or alternatively, that $R \& D$ and organization of production can be complementary in shifting surplus from labour to capital. The sign and significance of employment and output variables are stable across clusters.

Concerning the determinants of profits growth, we detect stability of signs and coefficients compared to the ones observed for the High-Low Tech clusters. The negative impact of wages doesn't hold for the 'Open' cluster. This result could be connected to the weakening of workers' bargaining power due to the relatively higher intensity of offshoring activities in such clusteras shown in Table 4. As expected and already found in the High-Low Tech estimation (Table 6) profits are mainly driven by export growth in the 'Open' cluster. Consequently, the growth of domestic demand positively affects profits in the 'Closed' industries.

The relevance of skill categories in shaping the relationship between wages and profits is analyzed in the next subsection. We report the results of the model estimated separately for each skill category. 


\subsection{The effect by skill level}

In this subsection, the rate of change of profits is analyzed in conjunction with the change of wages distinguished by skill categories. The wage equations are regressed against the same covariates as in the pooled model reported in the previous section, with the exception of the employment variable. The latter is referred to the change in employment of each skill category. In Table 8, 9 and 10 are contained, respectively, the results of the model considering the dynamics of profits and high, medium and low skilled workers' wages.

Table 8. The Wages-Profits 2SLS estimation (Profits vs High Skilled Wages)

\begin{tabular}{|c|c|c|}
\hline & (First Step) & (Second Step) \\
\hline & $\Delta$ Wages/hour & $\Delta$ Profits \\
\hline \multirow[t]{2}{*}{ R\&D expenditure } & 0.25 & \\
\hline & {$[0.08]^{* * *}$} & \\
\hline \multirow[t]{2}{*}{ R\&D expenditure (squared) } & -0.00 & \\
\hline & {$[0.00]^{*}$} & \\
\hline \multirow[t]{2}{*}{ Narrow Offshoring } & 0.27 & \\
\hline & {$[0.20]$} & \\
\hline \multirow[t]{2}{*}{ Narrow Offshoring (squared) } & 0.86 & \\
\hline & {$[0.33]^{*}$} & \\
\hline \multirow[t]{2}{*}{ R\&D expenditure * Narrow Offshoring } & -3.62 & \\
\hline & {$[1.09]^{* * *}$} & \\
\hline \multirow[t]{2}{*}{ Employment_HS (Rate of Growth) } & -0.36 & \\
\hline & {$[0.08]^{* * *}$} & \\
\hline \multirow[t]{2}{*}{ Gross Output (Rate of Growth) } & 0.42 & \\
\hline & {$[0.06]^{* * *}$} & \\
\hline \multirow[t]{2}{*}{$\Delta$ Wages/hour } & & -0.02 \\
\hline & & {$[0.60]$} \\
\hline \multirow[t]{2}{*}{ Expenditure for Mach. \& Equipments } & & 0.60 \\
\hline & & {$[0.35]^{*}$} \\
\hline \multirow[t]{2}{*}{ Exports (Rate of Growth) } & & 0.01 \\
\hline & & {$[0.01]$} \\
\hline \multirow[t]{2}{*}{ Domestic Demand (Rate of Growth) } & & 0.16 \\
\hline & & {$[0.06]^{* *}$} \\
\hline Dummies & Yes $^{* * *}$ & Yes $^{* * *}$ \\
\hline Observations & 541 & 489 \\
\hline R2 (Adj) & 0.40 & 0.20 \\
\hline
\end{tabular}

Dependent Variables: First Step (Compound annual rate of change of sectoral High Skilled hourly wages); Second Step (Compound annual rate of change of sectoral profits); Time and country dummies included. Adjusted Std. Errors in brackets. ${ }^{*}$ significant at $10 \%,{ }^{* *}$ significant at $5 \%,{ }^{* * *}$ significant at $1 \%$. 
The positive impact of innovation on wages is detected for each of the three skill categories. The concave shape of the innovation's impact on wages is detected only for high and medium skilled workers, while offshoring has a negative impact on wages only for medium and low skilled workers. This result could be associated to the relatively higher propensity of firms to offshore parts of the production process associated to medium and low skill activities.

Table 9. The Wages-Profits 2SLS estimation (Profits vs Medium Skilled Wages)

\begin{tabular}{|c|c|c|}
\hline & $\begin{array}{l}\text { (First Step) } \\
\Delta \text { Wages/hour }\end{array}$ & $\begin{array}{l}\text { (Second Step) } \\
\Delta \text { Profits }\end{array}$ \\
\hline R\&D expenditure & $\begin{array}{l}0.36 \\
{[0.06]^{* * *}}\end{array}$ & \\
\hline R\&D expenditure (squared) & $\begin{array}{l}-0.00 \\
{[0.00]^{* *}}\end{array}$ & \\
\hline Narrow Offshoring & $\begin{array}{l}0.30 \\
{[0.13]^{* * *}}\end{array}$ & \\
\hline Narrow Offshoring (squared) & $\begin{array}{l}0.33 \\
{[0.31]}\end{array}$ & \\
\hline $\mathrm{R} \& \mathrm{D}$ expenditure $*$ Narrow Offshoring & $\begin{array}{l}-2.65 \\
{[-1.08]}\end{array}$ & \\
\hline Employment_MS (Rate of Growth) & $\begin{array}{l}-0.35 \\
{[0.07]^{* * *}}\end{array}$ & \\
\hline Gross Output (Rate of Growth) & $\begin{array}{l}0.43 \\
{[0.05]^{* * *}}\end{array}$ & \\
\hline$\Delta$ Wages/hour & & $\begin{array}{l}-0.11 \\
{[0.56]}\end{array}$ \\
\hline Expenditure for Mach. \& Equipments & & $\begin{array}{l}0.63 \\
{[1.77]^{*}}\end{array}$ \\
\hline Exports (Rate of Growth) & & $\begin{array}{l}0.01 \\
{[0.01]}\end{array}$ \\
\hline Domestic Demand (Rate of Growth) & & $\begin{array}{l}0.16 \\
{[0.06]^{* *}}\end{array}$ \\
\hline Dummies & Yes $^{* * *}$ & $\mathrm{Yes}^{* * *}$ \\
\hline Observations & 541 & 489 \\
\hline R2 (Adj) & 0.56 & 0.15 \\
\hline
\end{tabular}


The interaction term - connecting R\&D efforts and offshoring - in the first step estimations is negative and significant only for the high skilled workers suggesting the prevalence of a negative pressure on wages for high skill workers in presence of both $R \& D$ and offshoring activities. Again, here the possibility is that in presence of workers with larger bargaining power, R\&D represents an important ingredient of work organization to reach the goal of increasing the profit share. Finally, the coefficients associated to the employment and the output variables are coherent in magnitude, significance, and sign with the estimations proposed in Section 4 for all the skill categories.

Table 10. The Wages-Profits 2SLS estimation (Profits vs Low Skilled Wages)

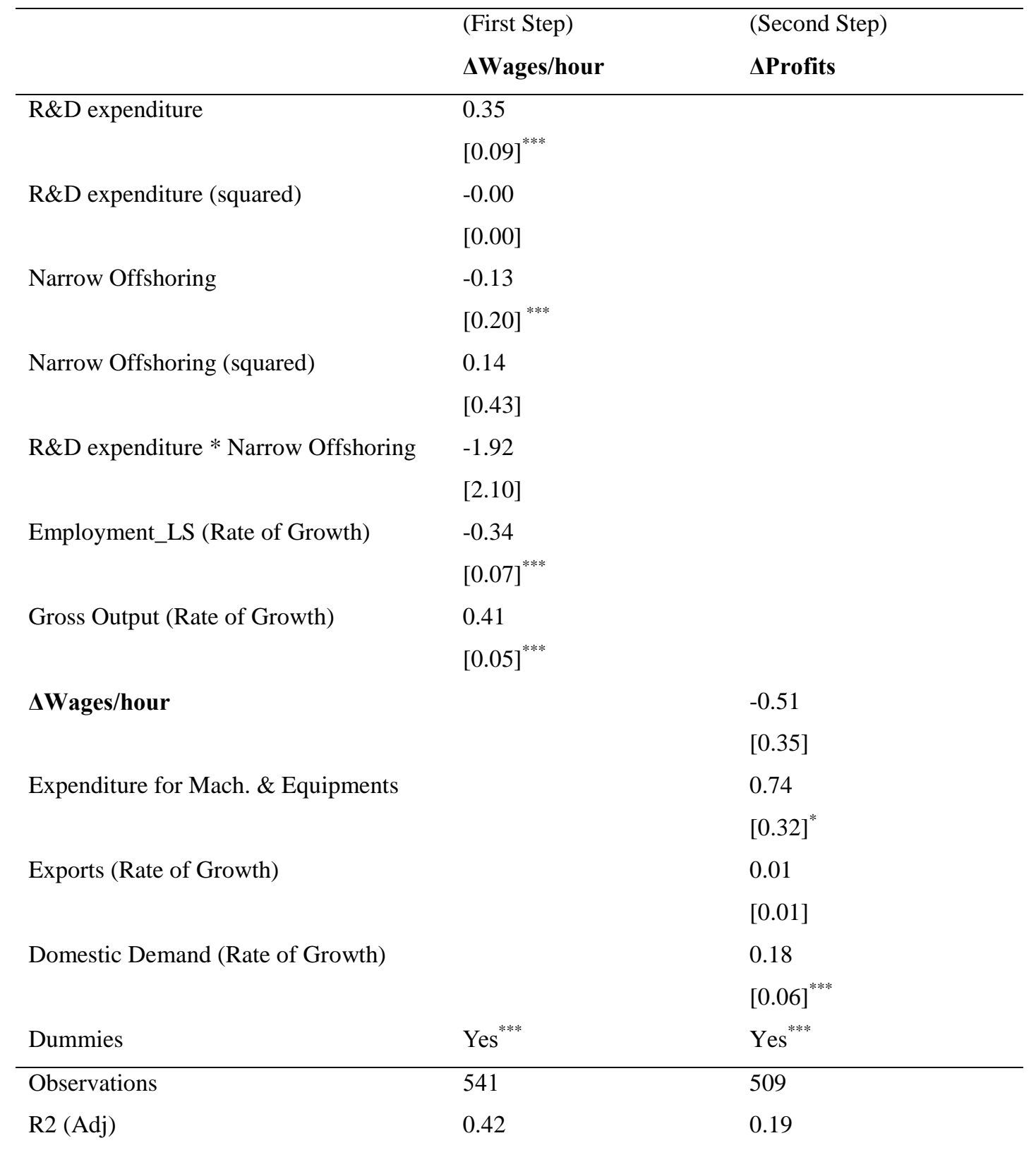

Dependent Variables: First Step (Compound annual rate of change of sectoral High Skilled hourly wages); Second Step (Compound annual rate of change of sectoral profits); Time, country and sectoral dummies included. Adjusted Std. Errors in brackets. ${ }^{*}$ significant at $10 \%,{ }^{* *}$ significant at $5 \%,{ }^{* * *}$ significant at $1 \%$. 
The identification of profits' determinants doesn't seem to be deeply reshaped by the consideration of each skill category separately. The variable capturing the change of wages is negative but not significant for all the skill categories: once separate workers group are considered, horizontal differences in bargaining power hide the basic capital labor structure. Investments and domestic demand are mainly driving profits dynamics supporting the thesis of profits led by demand. Therefore, the realization of profits is strongly connected with the presence of a sustained demand beside the investment component. ${ }^{16}$

\section{Conclusions}

In this contribution we address the capital-labour conflict as a fundamental nexus to understand the pattern of distribution across modern capitalist economies. We sketch a model based on two key statements: (1) wages are bargained according to planning decisions by the company, and the distributive conflict occurs over the surplus to be shared (as in a range theory of wages developed by Howell, 1999), where both technology (captured by R\&D) and international organization of production (captured by offshoring) contribute to define the distributive arrangement by shaping the bargaining power of the parties involved; (2) profits are realized if there is enough demand (as in the standard principle of effective demand), and different sources of demand are not necessarily homogeneous.

At the theoretical level, this work builds on the rent sharing hypothesis introduced by Van Reenen (1996) and further developed by Bogliacino (2014). The non-linear specification allows to frame better the complexity involved in the innovation-income distribution relationship. Furthermore, the inclusion of offshoring among the determinants of wages turned out to be crucial to complete the picture of the 'rent-sharing' bargaining scheme. Our results highlight that at present - and particularly in the more open sectors - offshoring is a key 'weapon' to threat workers within the bargaining process.

In such framework, heterogeneity turns out to be a crucial element affecting the set of inquired relationships from different points of view. From a structural perspective, the sectoral specificities in terms of technological trajectories - identified empirically by the detail of the adopted industry level data source, the use of Pavitt dummies in the estimation as well as the estimations implemented on separated High-Low tech clusters - seems to affect magnitude and direction of our relations. Remarkably, the relevance of innovation as a positive stimulus for wages - through the 'rent sharing' mechanism - is there only for the High Tech cluster of

\footnotetext{
${ }^{16}$ After distinguishing according to skill levels, the basic capital-labour conflict is softened because each skill category can grow at the expense of the others, in a horizontal conflict among workers.
} 
industries. ${ }^{17}$ Moreover, distinguishing explicitly between more and less 'globalized' industries is crucial for effectively capture the determinants of profits and wages within the distributive conflict. The more 'open' industry cluster turns out to be the most dynamic, with a strong impact of innovation - positively - and offshoring - negatively - affecting wages and a similar strong role of exports as profits drivers.

Heterogeneity emerges also in terms of skill structure, although this standard approach to understand distribution hides the general class structure, since each group of workers can grow at the expense of the other ones.

In terms of general implications, this work confirms the need to have a more strictly regulated institutional system in order to accomplish a smoother functioning of redistribution at the shopfloor level, and allow, at the same time, a more predictable rate of growth of internal demand, reducing the uncertainty related with capital accumulation and the pressure to increase profits share at the expenses of labour.

\section{References}

Acemoglu, D. (2002) Technical Change, Inequality, And The Labor Market, Journal of Economic Literature, 40(1), 7-72.

Acemoglu, D. and Autor, D. (2011). Skills, tasks and technologies: Implications for employment and earnings. In Ashenfelter, O. and Card, D. (eds.), Handbook of Labor Economics, (1 ed., Vol. 4, pp. 1043-1171). Elsevier.

Akerlof, G. A. and Yellen, J. (1990). The fair wage-effort hypothesis and unemployment. Quarterly Journal of Economics, 105(2), pp.255-283.

Amati, M., and Wei, S. (2004). Fear of Outsourcing: Is it Justified? (No. w.186). Washington: International Monetary Fund.

Antràs, P., Garicano, L. and Rossi-Hansberg, E. (2006). Offshoring in a knowledge economy. The Quarterly Journal of Economics, 121(1), pp. 31-77. MIT Press.

Arai, M. (2003). Wages, profits, and capital intensity: Evidence from matched worker-firm data, Journal of Labor Economics, vol. 21, no. 3, 593-618.

Arestis, Philip (1996). Post-Keynesian Economics: Towards Coherence. Cambridge Journal of Economics, 20(1), pp. 111-35.

Arpaia, A., Pérez E. and Pichelmann K. (2009). Understanding labour income share dynamics in Europe, MPRA Paper 15649, University Library of Munich, Germany.

Atkinson, A. B., Saez, E. and Piketty, T. (2011). Top Incomes in the Long Run of History. Journal of Economic Literature, 49(1), pp. 3-71.

\footnotetext{
${ }^{17}$ These results confirm the evidence provided in Guarascio et al. (2014).
} 
Atkinson, A. B. (1999) Is Rising Income Inequality Inevitable? A Critique of the Transatlantic Consensus. Wider Annual Lecture 3

Basu, D. and Vasudevan, R. (2013). Technology, distribution and the rate of profit in the US economy: understanding the current crisis. Cambridge Journal of Economics, 37(1), pp. 57-89. Oxford University Press.

Berman, E., Bound, J., and Griliches, Z. (1994). Changes in the demand for skilled labor within u.s. manufacturing: evidence from the annual survey of manufactures. Quarterly Journal of Economics, 109 (2), pp. 367-97.

Bogliacino, F. (2014). Innovation and employment: A firm level analysis with european R\&D Scoreboard data. Economia, ANPEC-Brazilian Association of Graduate Programs in Economics, 15(2), pp. 141-154.

Bogliacino, F. and Lucchese, M. (2015). Endogenous skill biased technical change: testing for demand pull effect. Industrial and Corporate Change, Oxford Journals, first published online April 2014, doi:10.1093/icc/dtv010

Bogliacino, F., and Maestri, V. (2014). Increasing economics inequalities? In W. Salverda, B. Nolan, D. Checchi, I. Marx, A. McKnight, and I. Tóth (Eds.). Changing Inequalities in Rich Countries: Analytical and Comparative Perspectives, pp. 15-48. Oxford University Press.

Bogliacino F. and Pianta M. (2013a). Profits, R\&D and Innovation: a Model and a Test. Industrial and Corporate Change, 22(3), pp. 649-678.

Bogliacino F. and Pianta M. (2013b). Innovation and Demand In Industry Dynamics. R\&D, New products and Profits. In A. Pyka and E.S. Andersen (Eds.). Long Term Economic Development. Berlin: Springer.

Bogliacino, F. and Pianta, M. (2015). The Pavitt Taxonomy, Revisited. Patterns Of Innovation In Manufacturing And Services (No. 012631). UN-RCE-CID.

G. Bottazzi and M. Grazzi (2010) Wage-size relation and the structure of work-force composition in Italian manufacturing firms, Cambridge Journal of Economics, Volume 34, Number 4 pp. 649-669.

Brunello, G. and Colussi, A. 1998. The employer size-wage effect: evidence from Italy, -Labor Economics, vol. 5, pp. 217-30.

Burstein, A. and Vogel, J. (2012) International trade, technology, and the skill premium. 2012 Meeting Papers 664, Society for Economic Dynamics.

Campa, J. and Goldberg, L. (1997). The evolving external orientation of manufacturing industries: evidence from four countries (No. w 5919). National Bureau of Economic Research. Checchi, D. and Garcia-Penalosa, C. (2010). Labour Market Institutions and the Personal Distribution of Income in the OECD. Economica, London School of Economics and Political Science, 77(307), pp. 413-450. 
Costinot, A. and Rodriguez-Clare, A. (2013). Trade Theory with Numbers: Quantifying the Consequences of Globalization (No. 9398). CEPR Discussion Papers.

Dasgupta, P. and Stiglitz, J. (1980). Industrial structure and the nature of innovative activity. The Economic Journal, pp. 266-293.

Davis, S. J. and Haltiwanger, J. (1991) Wage dispersion between and within U.S. manufacturing plants: 1963-86, Brookings Paper on Economic Activity, Microeconomics 1991, pp. 115-200.

Drandakis, E. and Phelps, E. (1966). A model of induced invention, growth, and distribution. Economic Journal, 76 (304), pp. 823-840.

Dosi, G. (1988). Sources, procedures and microeconomic effects of innovation. Journal of Economic Literature, vol. 26, pp.1120-1171.

Dunne, T. and Schmitz, J. A, (1995) Wages, Employment Structure and Employer Size-Wage Premia: Their Relationship to Advanced-Technology Usage at US Manufacturing Establishments, Economica, London School of Economics and Political Science, vol. 62(245), pages 89-107, February.

Feenstra, R. C. and G.H. Hanson (1996). Foreign investment, outsourcing and relative wages. In R.C. Feenstra, G.M. Grossman and D.A. Irwin, (eds.). The Political Economy of Trade Policy: Papers in Honor of Jagdish Bhagwati, pp. 89-127. MIT Press.

Feenstra, R. C. and Gordon H. H. (1997). Foreign Investment and Relative Wages: Evidence from Mexico’s Maquiladoras. Journal of International Economics, 42(3), pp. 371-393.

Feenstra, R.C. and G.H. Hanson (1999), 'The impact of outsourcing and high-technology capital on wages: Estimates for the United States, 1979-1990', Quarterly Journal of Economics, Vol. 114, pp. 907-941.

Fellner, W. (1961). Two Propositions in the Theory of Induced Innovations. Economic Journal, 71, pp. 305-308.

Fosse, H. and Maitra, M. (2012). Import, offshoring and wages: rent sharing or composition?

Mimeo, 2012. Available at: http://openarchive.cbs.dk/bitstream/handle/10398/8540/Fosse_2012_2.pdf?sequence=1

Foster N., Pöschl, J. and Stehrer, R. (2012) Offshoring and the Elasticity of Labour Demand, wiiw Working Papers 90, The Vienna Institute for International Economic Studies, wiiw.

Geishecker, I. and Görg, H. (2008). Winners and losers: A micro-level analysis of international outsourcing and wages. Canadian Journal of Economics, 41 (1), pp. 243-270.

Glass, J. and Saggi, K. (2001) Innovation and wage effects of international outsourcing, European Economic Review, Elsevier, vol. 45(1), pages 67-86, January.

Görg, H. and Hanley, A. (2011). Services outsourcing and innovation: an empirical investigation. Economic Inquiry, Western Economic Association International, 49(2), pp. 321333. 
Guarascio, D., Pianta, M. and Bogliacino, F. (2014). Export, R\&D and new products: A model and a test on european industries, Working paper 1406. University of Urbino DESP.

Guarascio, D., Pianta, M., Lucchese, M. and Bogliacino, F. (2015). Business cycles, technology and exports. Economia Politica - Journal of Analytical and Institutional Economics, 32(2), pp. 167-200. Springer International Publishing.

Hair, J.F. (2010). Multivariate data analysis: a global perspective, 7th edn. Upper Saddle River, N.J. London: Pearson.

Hicks, J. R. (1932). The theory of wages. MacMillan London.

Hijzen, A., Tomohiko I. and Yasuyuki T. (2010). Does offshoring pay? firm-level evidence from Japan. Economic Inquiry, 48(4), pp. 880-895.

Howell, D. R. (1999). Theory-Driven Facts and the Growth in Earnings Inequality. Review of Radical Political Economics, 31, pp. 54-86.

Hummels, D., Ishii, J., and Yi, K. M. (2001). The nature and growth of vertical specialization in world trade. Journal of International Economics, 54(1), pp. 959-972.

Hummels, D., Jorgensen, R., Munch, J. and Xiang, C. (2014). The wage effects of offshoring: evidence from danish matched worker-firm data. American Economic Review, 104(6), pp. 15971629.

International Labor Organization (2015). Global wage report: wages and income inequality. International Labour Organization.

Jayadev, A. (2007). Capital account openness and the labour share of income. Cambridge Journal of Economics, 31(3), pp. 423-443.

Kalecki, M. (1939). Essays in the theory of economic fluctuations. In Osiatynski, J. (2007). Collected works of M. Kalecki. Vol. I: Capitalism, business and full employment. Clarendon Press Oxford.

Kennedy, C. (1964). Induced bias in innovation and the theory of distribution. Economic Journal, 74 (295), pp. 541-547.

Kramarz, F. (2008). Offshoring, wages and employment: evidence form data matching imports, firms and workers. CREST-INSEE mimeo Available at: http://www.crest.fr/ckfinder/userfiles/files/pageperso/kramarz/offshoring072008.pdf

Lallemand, T., Plasman, R. and Rycx, F. 2005. 'The Establishment-size Wage Premium:

Evidence from European Countries', IZA Discussion Papers 1569, Institute for the Study of Labor (IZA).

Landesmann, M. Leitner, S. and Stehrer, R. (2015) Competitiveness of the European economy wiiw Research Report No. 401, May 2015

Lucchese, M. and Pianta, M. (2012). Innovation and Employment in Economic Cycles. Comparative Economic Studies, 54(2), pp. 341-359, June. Palgrave Macmillan. 
Malerba F. (ed.) (2004). Sectoral systems of innovation. Cambridge: Cambridge University Press.

Main, B. G. M. and Reilly, B. 1993. The employer size-wage gap: evidence from Britain, Economica, vol. 60, pp. 125-42.

Marx, K. (1867). A Critique of Political Economy, Vol. I. The Process of Capitalist Production. Frederick Engels, Ernest Untermann, eds. Samuel Moore, Edward Aveling, trans. 1906. Library of Economics and Liberty. 30 March 2015.

Milberg, W. and Winkler, D. (2010). Financialisation and the dynamics of offshoring in the USA. Cambridge Journal of Economics, 34(2), pp. 275-293, March. Oxford University Press.

Milberg, W. and Winkler, D. (2013). Outsourcing economics: Global value chains in capitalist development. Cambridge University Press.

OECD, (2011). Divided We Stand: Why Inequality Keeps Rising. OECD Publishing.

OECD, (2008). Growing Unequal? Income Distribution and Poverty in OECD Countries. OECD Publishing.

Perani, C. and Cirillo, V. (2015) Matching industry classifications. A method for converting Nace Rev.2 to Nace Rev.1 (No. 1502). University of Urbino Carlo Bo, Department of Economics, Society \& Politics - revised 2015.

Pianta M., Tancioni, M. (2008). Innovations, profits and wages. Journal of Post Keynesian Economics, 31(1), pp. 103-123.

Pianta M. and Lucchese M. (2011). The Sectoral Innovation Database 2011. Methodological Notes, University of Urbino, Faculty of Economics. Discussion Paper.

Piketty, T. (2014). Capital in the twenty-first century. Cambridge: Harvard University Press.

Ricardo, D. (1815). An Essay on the Effects of a Low Price of Corn on the Profits of Stock etc. In P. Sraffa, (ed.). Works and Correspondence of David Ricardo, 4. Cambridge: Cambridge University Press, 1951.

Salter, E. W. G. (1960). Productivity and technical change. Cambridge University Press. Cambridge, Mass, 1(6), 0.

Samuelson, P. A. (1965). A theory of induced innovations along Kennedy-Weisacker lines. Review of Economics and Statistics, 47, pp. 343-356.

Schlenker E. and Schmid D. (2013). Capital Income Shares and Income Inequality in the European Union (IMK Working Paper 119). IMK at the Hans Boeckler Foundation, Macroeconomic Policy Institute.

Schumpeter, J.A. (1975). Capitalism, Socialism and Democracy. New York: Harper (1st edn 1942).

Shapiro, C. and Stiglitz, J. (1984). Equilibrium unemployment as a worker discipline device. The American Economic Review, 74(3), pp. 433-444. 
Sheng, L. and Yang, D. T. (2012). The Ownership Structure of Offshoring and Wage Inequality: Theory and Evidence from China, mimeo. Available at: https://www.econ.cuhk.edu.hk/dept/seminar/12-13/1st-term/shengyang2012.pdf

Slaughter, M. J. (2000) Production transfer within multinational enterprises and American wages. Journal of International Economics, 50(2), pp. 449-72.

Stapel, S., J. Pasanen, and S. Reinecke (2004). Purchasing Power Parities and related economic indicators for EU, Candidate Countries and EFTA. Eurostat - Statistics in Focus.

Stockhammer, E. (2013). Why have wage shares fallen? A panel analysis of the determinants of functional income distribution (conditions of work and employment $\mathrm{N}^{\circ} 35$ ): for the International Labour Organisation (ILO) project" New Perspectives on Wages and Economic Growth" (No. 470913). International Labour Organization.

Stiglitz, J. (2012). The price of inequality: how today's divided society endangers our future. New York: W.W. Norton and Company editions.

Timmer, M., Los, B., Stehrer, R. and de Vries, G. (2013). Fragmentation, incomes and jobs: An analysis of European competitiveness. Economic Policy, 28 (76) pp.613-661.

Tridico, P. (2012). Financial crisis and global imbalances: its labour market origins and the aftermath. Cambridge Journal of Economics, 36(1), pp. 17-42. Oxford University Press.

Wooldridge, J. M. (1995). Score diagnostics for linear models estimated by two stage least squares. In Advances in Econometrics and Quantitative Economics: Essays in Honor of Professor C. R. Rao, ed. G. S. Maddala, P. C. B. Phillips, and T. N. Srinivasan, pp. 66-87. Oxford: Blackwell.

Van der Hoeven, R. (2014). Profits without labour benefits. The impact of financial globalization on work. Available at: http://www.thebrokeronline.eu/Articles/Profits-withoutlabour-benefits

Van Reenen, J. (1996). The creation and capture of rents: wages and innovation in a panel of u.k. companies. The Quarterly Journal of Economics, 111(1), pp. 195-226, February. MIT Press.

Vogel, J. and Burstein, A. (2012). International trade, technology, and the skill premium, Meeting Papers (No. 664). Society for Economic Dynamics.

Von Weizsäcker, C. (1966). Tentative notes on a two-sector model with induced technical progress. Review of Economic Studies, 33 (3), pp. 245-52.

Yamano, N., Ahmad, N., (2006). The OECD Input-Output Database: 2006 Edition, OECD Science, Technology and Industry Working Papers 2006/8. OECD Publishing.

Zamparelli, L. (2011). Induced Innovation, Endogenous Growth, and Income Distribution: a Model along Classical Lines (No. 1102). Dipartimento di Economia e Finanza, LUISS Guido Carli. 


\section{Appendix}

\section{A.1 Cluster analysis}

In order to group industries according to the intensity of offshoring, we perform a two-step cluster analysis applying single linkage algorithm and Gower's coefficient as similarity measure. As clustering variables, we consider both narrow definition of international outsourcing, which only considers imported intermediates in a given industry from the same industry (which corresponds to diagonal terms of the import-use matrix) and general imports. We cluster industrial sectors according to Feenstra and Hanson narrow offshoring indicators (FHN) (Feenstra and Hanson, 1996).

The two-step approach allows conducting first a hierarchical procedure to detect the number of existing groups and then a non-hierarchical clustering method having the advantage to reassign observations until maximum homogeneity within clusters is achieved (Hair et al., p. 553). This implies that the hierarchical procedure facilitates the assessment of groups in our sample as it is carried out in a stepwise fashion and trough an agglomerative method. Furthermore, the hierarchical approach permits to graphically evaluate the selected groups through a dendrogram.

Figure A1. Dendrogram of industries clustered according to offshoring intensity

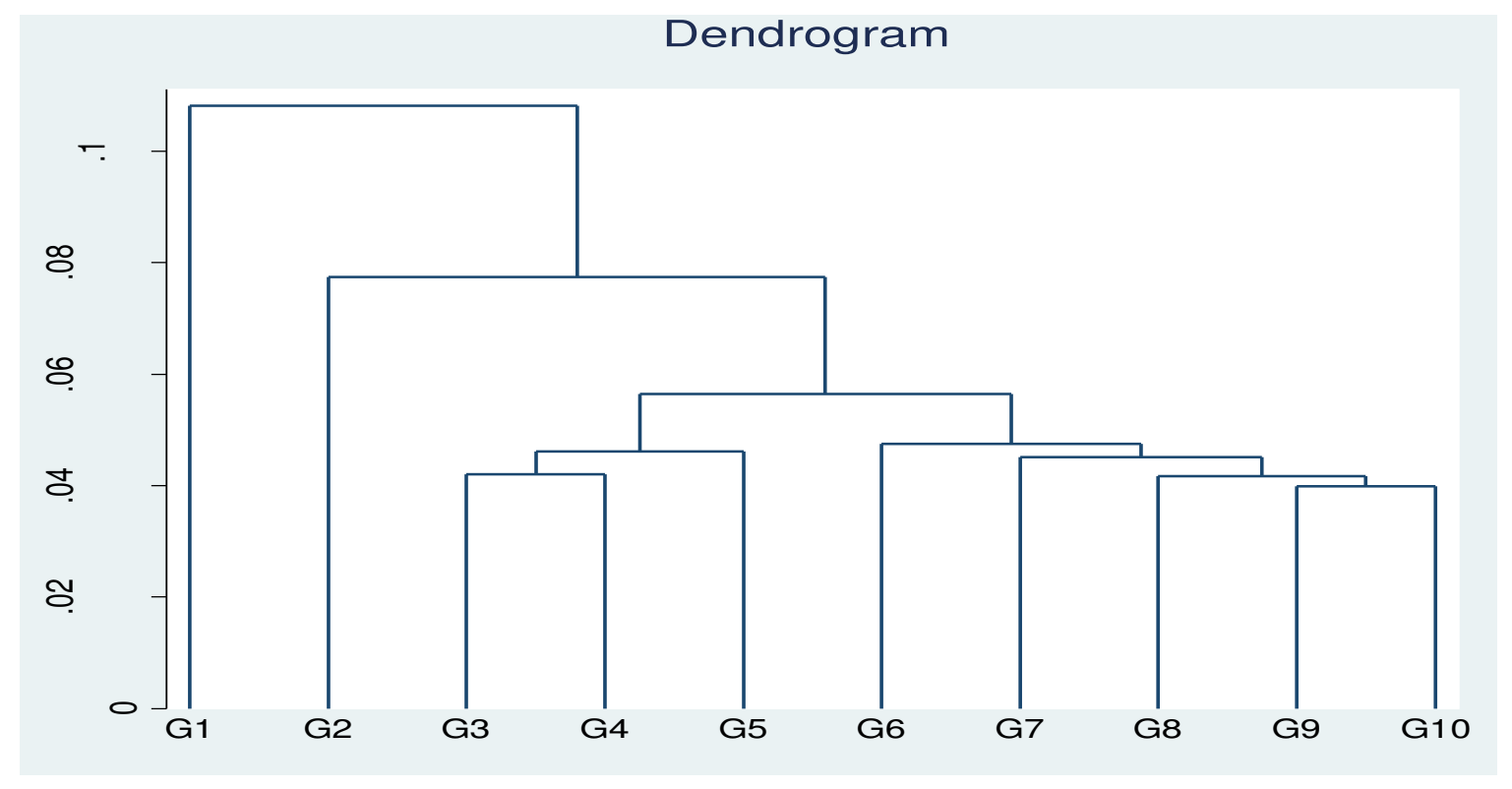

Source: Own elaboration on Sectoral Innovation Database (Pianta, 2011).

We apply as hierarchical clustering algorithm the single linkage clustering where the distance between two clusters is determined by a single element pair, namely those two elements (one in each cluster) that are closest to each other. The shortest of these links that remains at any step causes the fusion of the two clusters whose elements are involved (Hair, 2010). 
The Calinski-Harabasz pseudo-F stopping-rule index helps to identify the correct number of groups in the sample. Then, we perform a non-hierarchical clustering procedure based on kmeans method and again Gower's measure. The non-hierarchical procedure assigns objects into clusters given the number of cluster and optionally same starting points. The advantage of $\mathrm{K}$ means algorithm is to divide data into the number of clusters detected in the first hierarchical analysis and then iteratively reassigning observations to clusters till the distance of observations in the same cluster is minimized and the distance between clusters is maximized.

The two-step cluster analysis shows a 4 groups cluster solution.

Table A1. The two step cluster analysis - Descriptive statistics

\begin{tabular}{cccccccccccccc}
\hline & \multicolumn{3}{c}{ Cluster 1 } & \multicolumn{3}{c}{ Cluster 2 } & \multicolumn{3}{c}{ Cluster 3 } & \multicolumn{2}{c}{ Cluster 4 } \\
\hline Variable & Obs & Mean & Std. Dev. & Obs & Mea & St. Dev. Obs & Mean & St. Dev. Obs & Mean St. Dev. \\
Intra-sectoral import index & 6 & 0.25 & 0.03 & 37 & 0 & 0.02 & 41 & 0.10 & 0.02 & 101 & 0.02 & 0.02 \\
General import index & 6 & 0.16 & 0.00 & 37 & 0.11 & 0.01 & 41 & 0.06 & 0.02 & 101 & 0.01 & 0.01 \\
\hline
\end{tabular}

Source: authors' elaboration.

Due to the small number of observations, we merge cluster 1 and 2, and cluster 3 and 4 in order to create two major groups: 'Open' and 'Closed' sectors. The following table presents the main differences between closed and open sectors showing the mean values of the offshoring indexes applied. The mean difference between the two groups is statistically different at $5 \%$ of confidence level $(\mathrm{t}=-24.34 ; \mathrm{p}$-value $=0.00)$.

Table A2. The 'Open' and 'Closed' clusters - Descriptive statistics

\begin{tabular}{lcccccc}
\hline & \multicolumn{3}{c}{ Closed sectors } & \multicolumn{3}{c}{ Open sectors } \\
\hline \multicolumn{1}{c}{ Variable } & Obs & Mean & Std. Dev. & Obs & Mean & Std. Dev. \\
$\begin{array}{l}\text { Intra-sectoral } \\
\text { import index }\end{array}$ & 142 & 0.04 & 0.04 & 43 & 0.19 & 0.03 \\
$\begin{array}{l}\text { General import } \\
\text { index }\end{array}$ & 142 & 0.02 & 0.02 & 43 & 0.12 & 0.02 \\
\hline
\end{tabular}

Source: authors' elaboration.

\section{A.2 Robustness check}

This Section of the Appendix provides the robustness check for the econometric model of profits and wages determinants. The diagnostic test concerns four main issues: multicollinearity and endogeneity of variables, heteroscedasticity of errors and the overidentification test on instruments. In Table A3 the results of the multicollinearity and heteroskedasticity tests performed for the whole sample model - are presented. 
Table A3. The whole sample model - robustness check

\begin{tabular}{lll}
\hline & Profit equation & Wage equation \\
\hline Breusch-Pagan Test & 48.01 & 69.02 \\
Chi2(1) & 0.0000 & 0.0000 \\
p-value & & \\
Multicollinearity & 1.53 & 3.45 \\
Variance Inflation Factor (average) & Source: elaborate by authors.
\end{tabular}

Source: elaborate by authors.

In Table A4 and A5 we present the same test - first for profit and then for the wage equation for the model estimated distinguishing between high, medium and low skilled workers' wages.

Table A4. The high, medium and low skilled models - Profit equation robustness check

\begin{tabular}{llll}
\hline & High skill & Medium skill & Low skill \\
\hline Breusch-Pagan Test & & & 49.78 \\
Chi2(1) & 51.95 & 48.75 & 0.0000 \\
p-value & 0.0000 & 0.0000 & \multirow{2}{*}{1.56} \\
Multicollinearity & & \multirow{2}{*}{1.54} & \\
Variance Inflation Factor (average) & 1.55 &
\end{tabular}

Table A5. The high, medium and low skilled models - Wage equation robustness check

\begin{tabular}{llll}
\hline & High skill & Medium skill & Low skill \\
\hline Breusch-Pagan Test & & & \\
Chi2(1) & 38.50 & 24.62 & 11.67 \\
p-value & 0.0000 & 0.0000 & 0.0006 \\
Multicollinearity & & & \\
Variance Inflation Factor (average) & 3.45 & 3.46 & 3.46 \\
\hline
\end{tabular}

Source: elaborate by authors.

Multicollinearity is not an issue since all the values are below the threshold. ${ }^{18}$ Concerning heteroscedasticity, the test rejects the null hypothesis of constant variance for all the considered equations. So, we used the robust standard errors in order to achieve efficiency in our estimations.

The tests concerning variables' endogenity are provided as follows. First, in order to ensure the consistency of our wages and profits specification, we implemented an OLS-IV estimation of equation (3) and (5). In particular, the test regards $R \& D$ expenditure, employment and gross

${ }^{18}$ Usually VIF is considered worrisome if it is higher than ten (or higher than four, according to different sources), and these thresholds are both higher than the value of our sample statistics. 
output for wages; domestic demand and expenditure for new machineries in the case of profits. All the variables are potentially affected by simultaneity-related endogeneity. Thus, we run separate OLS IV regression of wages and profits equation, using as instruments the lags of variables suspected of endogeneity. The results of the post estimation tests - Durbin and Wu Hausman test on variables exogeneity - on each single variable are reported in table A6 ${ }^{19}$.

Second, we performed an overidentification test on instruments to check the robustness of the whole sample model in table 5. The results of the test on instruments are contained in Table A7 for both the whole sample and the high, medium and low skill models.

Third, we report the result (table A8) of a simple OLS estimation of wages implemented avoiding the inclusion of employment and gross output as covariates. Such test aims to ascertain the absence of biases - introduced by the potential simultaneity involving sectoral wages, gross output and employment variations - as well as to inquire the strength of the relationship between wages, innovation and offshoring variables.

Table A6. OLS IV estimations - Wu Hausman and Durbin tests

\begin{tabular}{llllll}
\hline $\begin{array}{l}\mathrm{H}_{0} \text { : variables are } \\
\text { exogenous }\end{array}$ & $\begin{array}{l}\mathrm{R} \& \mathrm{D} \\
\text { expenditure } \\
\text { (wage eq.) }\end{array}$ & $\begin{array}{l}\text { Gross } \\
\text { output } \\
\text { (wage eq.) }\end{array}$ & $\begin{array}{l}\text { Employmen } \\
\mathrm{t} \\
\text { (wage eq.) }\end{array}$ & $\begin{array}{l}\text { Expenditure } \\
\text { for new } \\
\text { mach. } \\
\text { (profits eq.) }\end{array}$ & $\begin{array}{l}\text { Domestic } \\
\text { demand } \\
\text { (profits eq.) }\end{array}$ \\
\hline $\begin{array}{l}\text { Durbin Score } \\
\text { Chi2(1) }\end{array}$ & 1.94 & 3.23 & 3.43 & 0.41 & 1.48 \\
$\begin{array}{l}\text { p-value } \\
\text { Wu Hausman }\end{array}$ & 0.16 & 0.08 & 0.07 & 0.51 & 0.22 \\
$\begin{array}{l}\mathrm{F}(1,348) \\
\text { p-value }\end{array}$ & 1.91 & 3.20 & 3.39 & 0.40 & 1.41 \\
& 0.16 & 0.08 & 0.07 & 0.52 & 0.23
\end{tabular}

Table A7. The Wages OLS estimation (robustness check)

\begin{tabular}{ll}
\hline & $\Delta$ Wages/hour \\
\hline R\&D expenditure & 0.47 \\
& {$[0.05]^{* * *}$} \\
R\&D expenditure (squared) & -0.00 \\
& {$[0.00]^{* *}$} \\
Narrow Offshoring & -0.42 \\
& {$[0.13]^{* *}$} \\
Narrow Offshoring (squared) & 0.05 \\
& {$[0.02]$} \\
R\&D expenditure * Narrow Offshoring & 0.00 \\
& {$[0.01]$} \\
\hline Observations & 541 \\
R2 & 0.30 \\
Prob $>$ F & 0.0000 \\
\hline
\end{tabular}

Dependent Variables: Compound annual rate of change of sectoral hourly wages

Std. Errors in brackets. ${ }^{*}$ significant at $10 \%,{ }^{* *}$ significant at $5 \%,{ }^{* * *}$ significant at $1 \%$.

\footnotetext{
${ }^{19}$ The Durbin and Wu Hausman tests' null hypothesis supports explanatory variable's exogeneity and, in case of acceptance of such hypothesis, allows for the use of OLS - or GLS in presence of heteroscedasticity - which, therefore, provides consistent estimations.
} 
Table A8. Overidentification test - Whole sample and High, Medium and Low skill models

\begin{tabular}{lllll}
\hline & Whole sample & High skill & Med. skill & Low skill \\
\hline Wooldridge Score Test & & & \\
Chi2(5) & 11.03 & 10.00 & 6.42 & 3.15 \\
P-value & 0.08 & 0.07 & 0.26 & 0.67 \\
\hline \multicolumn{5}{c}{ Source: elaborate by authors. }
\end{tabular}

The results of the test in table A6 give support to the exogeneity assumption for all the analyzed variables (all the p-values are above the 0.05 threshold). As expected, the exogeneity assumption is supported with different degrees of strength among variables. Concerning the wage equation, $R \& D$ expenditure turns out to be strongly exogenous according to the tests' statistics (p-value: 0.16); gross output and employment variation result to be exogenous as well, but with a relatively lower degree of significance (p-values: 0.07). Looking at profit equation, the exogeneity of expenditure for new machineries and variation of domestic demand is confirmed by the figures in table A6 (p-values are, respectively, 0.51 and 0.22 ). Such outcome gives a substantial support to our econometric strategy - namely, using variables' time structure and controlling for time, country and sector specific fixed effects as a way to address endogeneity issues in such industry-level context - as well as to our results' reliability.

The outcome in table A7 gives a further confirmation concerning the adopted specification. The exclusion of gross output and employment variation does not affect the key relationships identified in Section 3. Finally, the statistics in Table A8 confirm the validity of the selected instruments and the proper identification of the models. In particular, all the reported p-values are above the 0.05 threshold supporting the validity of our instruments at the $5 \%$ significance level.

As anticipated in Section 3.1, we checked the reliability of the FHN as an offshoring indicator and the absence of biases in our sample selection due to the adoption of the latter. With this purpose, Table A9 provides the Pearson's rho coefficients comparing the FHN and the full set of offshoring indicators: (1) the Feenstra and Hanson broad offshoring indicator which, differently form the FHN, consider for each industry the flow of intermediate inputs imported for all the foreign industries; (2) the extension of the FHN proposed by Guarascio et al. (2014) where intermediate inputs are grouped in an High Tech and a Low Tech cluster; (3) the FHN computed considering manufacturing industries only. As it can be seen, the level of correlation is very high and statistically significant.

Finally, we report a test aimed at verifying the reliability of clustered - High versus Low-tech and Open versus Closed industries - estimations contained in Tables 6 and 7. Tables A10 and A11 present the results of the Chow Test informing whether the regression coefficients estimated on different data sets are significantly different one from each other. 
Table A9. Correlation between the FHN and other offshoring indicators

\begin{tabular}{lll}
\hline & $\begin{array}{l}\text { Correlation } \\
\text { coefficient }\end{array}$ & $\begin{array}{l}\text { P-value } \\
(5 \% \text { sign. level })\end{array}$ \\
\hline Feenstra and Hanson broad & 0.83 & 0.00 \\
High tech offshoring & 0.77 & 0.00 \\
Low tech offshoring & 0.75 & 0.00 \\
Feenstra and Hanson narrow (manufacturing) & 0.76 & 0.00 \\
\hline
\end{tabular}

Source: elaborate by authors.

Table A10. The Chow test - High versus low-tech clusters

\begin{tabular}{lll}
\hline & Profit equation & Wage equation \\
\hline $\mathrm{F}(7,533)$ & 15.04 & \\
$\mathrm{p}$-value & 0.00 & \\
$\mathrm{~F}(4,518)$ & 4.38 \\
$\mathrm{p}$-value & 0.00 \\
\hline
\end{tabular}

Table A11. The Chow test - Open versus closed clusters

\begin{tabular}{lll}
\hline & $\begin{array}{l}\text { Profit } \\
\text { equation }\end{array}$ & $\begin{array}{l}\text { Wage } \\
\text { equation }\end{array}$ \\
\hline $\mathrm{F}(7,533)$ & 15.48 & \\
p-value & 0.00 & \\
F $(4,518)$ & & 7.60 \\
p-value & & 0.00 \\
\hline
\end{tabular}

Source: elaborate by authors.

The results of proposed specification tests support the proposed grouping of industries as underlined in Section 4.2. 